\title{
CONTROL OF MICROENVIRONMENTAL CUES WITH A SMART BIOMATERIAL COMPOSITE PROMOTES ENDOTHELIAL PROGENITOR CELL ANGIOGENESIS
}

\author{
Aitor Aguirre ${ }^{1,2,3}$, Arlyng González ${ }^{1,3}$, Melba Navarro ${ }^{1,2,3}$, Óscar Castaño ${ }^{1,3}$, \\ Josep A. Planell ${ }^{1,2,3}$ and Elisabeth Engel ${ }^{1,2,3, *}$ \\ ${ }^{1}$ Institute for Bioengineering of Catalonia, Barcelona, Spain. \\ ${ }^{2}$ Technical University of Catalonia, Barcelona, Spain. \\ ${ }^{3}$ CIBER-BBN, Zaragoza, Spain.
}

\begin{abstract}
Smart biomaterials play a key role when aiming at successful tissue repair by means of regenerative medicine approaches, and are expected to contain chemical as well as mechanical cues that will guide the regenerative process. Recent advances in the understanding of stem cell biology and mechanosensing have shed new light onto the importance of the local microenvironment in determining cell fate. Herein we report the biological properties of a bioactive, biodegradable calcium phosphate glass/polylactic acid composite biomaterial that promotes bone marrowderived endothelial progenitor cell (EPC) mobilisation, differentiation and angiogenesis through the creation of a controlled bone healing-like microenvironment. The angiogenic response is triggered by biochemical and mechanical cues provided by the composite, which activate two synergistic cell signalling pathways: a biochemical one mediated by the calcium-sensing receptor and a mechanosensitive one regulated by non-muscle myosin II contraction. Together, these signals promote a synergistic response by activating EPCs-mediated VEGF and VEGFR-2 synthesis, which in turn promote progenitor cell homing, differentiation and tubulogenesis. These findings highlight the importance of controlling microenvironmental cues for stem/progenitor cell tissue engineering and offer exciting new therapeutical opportunities for biomaterialbased vascularisation approaches and clinical applications.
\end{abstract}

Keywords: Calcium phosphate glass composite; smart biomaterial; endothelial progenitor cell; angiogenesis; mechanosensing; calcium-sensing receptor.

\author{
*Address for correspondence: \\ Elisabeth Engel, PhD \\ Biomaterials for Regenerative Therapies Group \\ Institute for Bioengineering of Catalonia \\ Baldiri Reixac 15-21 \\ Barcelona \\ Spain
}

Telephone Number: +34 934020210

FAX Number: +34 934020183

E-mail: elisabeth.engel@upc.edu

\section{Introduction}

Regenerative medicine and tissue engineering implantation approaches rely strongly on two strategies to promote repair of the target tissue: a) the implantation of devices or constructs containing relevant in vitro cultured cells (classical tissue engineering), or b) biomaterials containing chemical or physical cues inducing the mobilisation of host cells capable of exerting the desired effects (in situ tissue engineering) (Hench and Polak, 2002; Lutolf et al., 2009; Mooney and Vandenburgh, 2008; Rehfeldt et al., 2007). From a practical point of view, the second approach is easier to implement in the clinic. Between 2002 and 2004 , the concept of smart biomaterials was introduced (also known as intelligent biomaterials or $3^{\text {rd }}$ generation) (Hench and Polak, 2002; Anderson et al., 2004). In brief, these biomaterials possess two essential properties: biodegradability (they are resorbed into the host's body without secondary effects) and bioactivity (they elicit a specific cell response) that make them suitable candidates for the application of in situ tissue engineering strategies (Hench and Polak, 2002).

The lack of proper vascularisation in implanted biomaterials has largely hindered the efforts made to provide successful tissue substitutes. Most biomaterials fail from the start because improper blood supply leads to cell death at the implant site prompted by scarceness of nutrients (including $\mathrm{O}_{2}$ ), accumulation of waste products, impaired biochemical signalling and abnormal cell recruitment, resulting in an overall poor host integration (Santos and Reis, 2010). These problems can be circumvented by improving vascularisation in the local environment of the implant, and many efforts have been directed to clarify or solve the problem, mostly employing prevascularised or endothelialised constructs (Forster et al., 2011; Kneser et al., 2006). An alternative possibility implies the use of proangiogenic smart biomaterials able to recruit cells that actively participate in angiogenesis in vivo, such as endothelial progenitor cells (EPCs) (Larrivée and Karsan, 2007; Nomi et al., 2002). This would greatly simplify the preparation of the biomaterial previous to implantation, but more importantly, would facilitate vascularisation to proceed as in vivo, that is, coordinated with the host's healing response (Nomi et al., 2002).

EPCs are a heterogeneous subpopulation of bone marrow mononuclear progenitor cells with potential for differentiation to the endothelial lineage and demonstrated vasculogenic capacity (Asahara et al., 1997). In physiological conditions, EPCs are mobilised by growth factors and cytokines to the peripheral circulation, where 
they home to sites of new vessel growth during injury or trauma (Takahashi et al., 1999). Since EPCs are a natural source of angiogenic cells and can be mobilised by biochemical stimuli, they are an attractive target of interest for vascularisation-oriented tissue engineering approaches and as such have received considerable attention in the last decade (Fuchs et al., 2006).

In the context of bone tissue engineering, angiogenesis and osteogenesis are intimately linked, and it has been long suspected that both processes need to be correctly regulated for bone regeneration to occur (Aguirre et al., 2010b; Kanczler and Oreffo, 2008; Kirkpatrick et al., 2011; Li et al., 2011). This observation is true for muscular tissue too, given that it relies heavily on blood supply for its function (Koffler et al., 2011). In the case of bone, matrix formation starts with osteoblast-mediated collagen I deposition to form osteoid with angiogenesis occurring almost simultaneously. The matrix is gradually mineralised acquiring properties of mature bone (Kanczler and Oreffo, 2008). These bone healing sites consist of a complex mixture of mechanical signals determined by the matrix stiffness, and biochemical cues (growth factors, cytokines and ions). Together, these components establish a highly specific microenvironment that directs cell fate and tissue maturation. Initially, matrix elasticity properties of the bone healing microenvironment are mainly dictated by collagen I. Osteoid has an initial stiffness in the 30 $40 \mathrm{kPa}$ range and increases as mineral deposition takes place (Engler et al., 2006). Mechanical forces exerted by the cells alter their shape and function through focal adhesions and actomyosin contraction, which lead to activation of intracellular signalling pathways (Ingber, 2006; Ingber, 2008; Mammoto and Ingber, 2009, Engler et al., 2006). The process has been shown to be dependent on a non-muscle myosin II-dependent pathway that can be decoupled with the use of blebbistatin (a specific myosin inhibitor). A role for mechanosensing has been observed in endothelial cells, in which matrix elasticity dictates VEGFR-2 expression changes (Mammoto et al., 2009; Mammoto et al., 2008). This mechanism enhances angiogenesis in matrices with elastic properties similar to those of blood vessel extracellular matrix (ECM).

From a biochemical perspective, recent evidence suggests that the calcium-sensing receptor (CaSR), a membrane-bound $\mathrm{G}$ protein-coupled receptor, is involved in a biochemical pathway resulting in EPC recruitment and modulation of EPC-mediated angiogenesis (Aguirre et al., 2010a). It is well-established that calcium acting through the CaSR promotes proliferation and differentiation in several cell types, including effects on endothelial cells, but also promotes important changes in bone cells such as osteoblasts and osteoclasts (Brown and MacLeod, 2001; Mentaverri et al., 2006). Tissue-specific CaSR deficient mice exhibit grave defects in bone and cartilage, highlighting the importance of this poorly studied receptor in many physiological processes (Chang et al., 2008). In vivo experiments indicate that bone marrow progenitor cells are mobilised to sites of high calcium concentration - such as calcium releasing biomaterials - possibly by CaSR-mediated chemotaxis, suggesting a role of these cells in high extracellular calcium environments like resorbing bone (Adams et al., 2006; Tommila et al., 2009).

The aim of this work was to explore the potential biological properties of a smart polylactic acid (PLA)/ calcium phosphate glass composite biomaterial over endothelial progenitor cells. The material, which was designed for in situ bone regeneration and vascularisation, has been described in detail before (Navarro et al., 2004). It mimics two of the bone healing microenvironment properties previously described: high extracellular calcium concentration and matrix stiffness analogous to osteoid. For these reasons, we hypothesised that our glass-based composite could induce a controlled angiogenic response when in contact with relevant stem cells involved in vascularisation, and thus we designed an in vitro assay model aimed at evaluating its proangiogenic performance. This system was also suitable for the study of biochemical (extracellular calcium) and mechanical cues (matrix stiffness) involved in the process.

\section{Materials and Methods}

\section{Bioactive glass fabrication}

Bioactive soluble glass (G5 glass) was produced in the system $44.5 \mathrm{P}_{2} \mathrm{O}_{5}-44.5 \mathrm{CaO}-6 \mathrm{Na}_{2} \mathrm{O}-5 \mathrm{TiO}_{2}$ (molar \%). For its fabrication, a homogeneous mixture of $\mathrm{NH}_{4} \mathrm{H}_{2} \mathrm{PO}_{4}$, $\mathrm{Na}_{2} \mathrm{CO}_{3}, \mathrm{CaCO}_{3}$ and $\mathrm{TiO}_{2}$ was melted in a platinum crucible at $1,350{ }^{\circ} \mathrm{C}$ for $3 \mathrm{~h}$, rapidly quenched and annealed at its transition temperature $\left(533^{\circ} \mathrm{C}\right)$. Glass particles were obtained after milling in an agate planetary mill.

\section{Fabrication of the composites}

The biodegradable composites were elaborated by the solvent-casting method using $\mathrm{NaCl}$ as a porogen agent. PLA was dissolved in chloroform ( $5 \%$ solution $\mathrm{w} / \mathrm{v})$ on an orbital shaker at $200 \mathrm{rpm}$. $\mathrm{NaCl}$ particles in the range of 80-210 $\mu \mathrm{m}$ and glass particles of $<40 \mu \mathrm{m}$ size were then added and mixed to create an homogeneous paste that was cast in Teflon moulds (6 mm diameter, $12 \mathrm{~mm}$ length). Once the chloroform had evaporated at room temperature the scaffolds were removed from the moulds, immersed in distilled water for two days (3 water changes per day) to eliminate the $\mathrm{NaCl}$ and left to dry in air. The resulting structures presented a highly interconnected porosity ( $\sim 95 \%$ ), with a pore size diameter in the $80-210 \mu \mathrm{m}$ range. Calcium phosphate glass films were generated by the sol-gel method using titanium, calcium, sodium and phosphorus alkoxides as precursors mixed in a proper ratio. The gels obtained were spin-coated for film production on flat Pyrex substrates. Films were then treated at $530{ }^{\circ} \mathrm{C}$ to eliminate organics and reach the final glass structure and composition.

\section{Cell seeding on the biomaterials}

The scaffolds were cut into $3 \mathrm{~mm}$ thick slices, sterilised by immersion in $70 \%$ ethanol for $1 \mathrm{~min}$, rinsed in PBS and pre-incubated for $24 \mathrm{~h}$ in complete medium at $37^{\circ} \mathrm{C}$. Cells were seeded at a density of 40,000 cells/disc in 96well plates. In the case of G5 glass films, sterilisation was 
carried out by brief immersion in $70 \%$ ethanol followed by rinsing in phosphate-buffered saline (PBS) and preincubation in complete medium. 80,000 cells/film were seeded on the film in 6-well plates at $37^{\circ} \mathrm{C}$.

\section{Isolation of rat bone marrow-derived endothelial progenitors}

The protocol and the cell characterisation have been published elsewhere (Aguirre et al., 2010a; Liu et al., 2007). In brief, bone-marrow was obtained from the long bones of young Lewis rats (2-4 weeks old) and the whole cellular fraction was resuspended in M199 (Sigma, St. Louis, MO, USA) supplemented with $20 \%$ foetal bovine serum (FBS), $1 \%$ pyruvate (Pyr), $1 \%$ penicillin/ streptomycin (Pen/strep), 1 \% L-glutamine (L-glu, Invitrogen, New York, NY, USA) and $22 \mu \mathrm{g} / \mathrm{mL}$ heparin (Sigma) and was plated in $1 \mu \mathrm{g} / \mathrm{mL}$ fibronectin-coated 6-well plates (Nunc, Roskilde, Denmark) and incubated for $24 \mathrm{~h}$. Most adherent cells attached to the dish in this period, including mesenchymal stem cells, immature leukocytes, mature endothelial cells from vessels and others. The cells in suspension were then recovered and plated in new dishes for another $24 \mathrm{~h}$. On the third day the suspension fraction, at this point highly enriched in haematopoietic cells, was again replated, this time with medium favouring EPC growth consisting of M199, $20 \%$ FBS, $1 \%$ Pyr, $1 \%$ Pen/Strep, $1 \%$ L-glu, $22 \mu \mathrm{g} / \mathrm{mL}$ heparin, $20 \mathrm{ng} / \mathrm{mL}$ VEGF, $5 \mathrm{ng} / \mathrm{mL}$ bFGF, $20 \mathrm{ng} / \mathrm{mL}$ IGF1, $5 \mathrm{ng} / \mathrm{mL}$ EGF (Peprotech, Rocky Hill, NJ, USA) and $1 \mu \mathrm{g} / \mathrm{mL}$ ascorbate. Cells reached confluence after 8-9 d and were characterised as EPCs by both phenotypical and functional assays. Over time in culture, cells would lose progenitor-like properties and start to differentiate towards a more mature endothelial phenotype. To prevent this, only early passage cells were used in the experiments.

\section{WST-1 cell viability and proliferation assay}

Cells seeded at a density of 10,000 cells/well in 96-well plates and cultured in complete medium were incubated for $1 \mathrm{~h}$ with 1:10 WST-1 reagent (Roche Applied Science, Indianapolis, IN, USA) to determine mitochondrial dehydrogenase activity. The supernatant was taken to an ELISA plate reader to measure formazan dye formation by absorption at $450 \mathrm{~nm}$.

\section{Fluorescent determination of free calcium}

A low-affinity fluorescent calcium indicator suitable for measurements of free calcium in cell culture medium was employed to determine calcium release from the material in cell-free conditions (Rhod-5N, Invitrogen). Rhod-5N binds strongly to calcium, being excited at $552 \mathrm{~nm}$ and emitting at $581 \mathrm{~nm}$. Medium samples were collected from control or biomaterial-incubated samples. A final concentration of $1 \mu \mathrm{M}$ Rhod-5N was applied. A spectrofluorimeter (Shimadzu, Columbia, MD, USA) was then used to determine fluorescence emission. Fluorescence intensity values were extrapolated to the data obtained from a standard curve of known free calcium concentrations (ranging from 0 to $100 \mathrm{mM}$ calcium).

\section{Blebbistatin and CaSR antibody treatments}

Blebbistatin (Sigma) was dissolved in DMSO and used at a final concentration of $20 \mu \mathrm{M}$. It was applied $4 \mathrm{~h}$ after cell seeding for 24 hour-long experiments or $24 \mathrm{~h}$ after seeding for 3 day-long experiments (it has been demonstrated that it is stable for up to $3 \mathrm{~d}$ in culture). It was verified that blebbistatin did not have negative effects on cell survival or chemotaxis (data not shown). CaSR antibodies (Affinity Bioreagents, Rockford, IL, USA) were used to block biochemical signalling through the calcium-sensing receptor (dilution 1:100). They were applied in the same pattern used for blebbistatin.

\section{Immunofluorescence and microscopic imaging}

Acridine orange (AO, Sigma) was used to visually determine cell morphology, distribution and number. Cells were incubated for $10 \mathrm{~min}$ with $10 \mu \mathrm{g} / \mathrm{mL} \mathrm{AO}$ and washed twice with PBS. Imaging was performed with a stereomicroscope (Leica, Wetzlar, Germany) coupled to a CCD camera. For immunofluorescence, cells were cultured on glass coverslips or material for $24 \mathrm{~h}$ and fixed in $3 \%$ paraformaldehyde for $10 \mathrm{~min}$, blocked with $6 \%$ bovine serum albumin (BSA) in PBS and permeabilised with $0.1 \%$ TX-100 solution for $10 \mathrm{~min}$. Afterwards, they were incubated overnight at $4{ }^{\circ} \mathrm{C}$ with the following primary anti-rat antibodies: CaSR (Affinity Bioreagents), GATA2 (Santa Cruz, Santa Cruz, CA, USA), TFII-I (BecktonDickinson, Franklin Lakes, NJ, USA), NF-кB (Millipore, Billerica, MA, USA) and vinculin (Sigma), followed by incubation with secondary Alexa-488 fluorescent antibodies (Invitrogen) for $1 \mathrm{~h}$ at $37^{\circ} \mathrm{C}$. Counterstaining was performed with phalloidin-rhodamine and DAPI (Invitrogen). Cells incubated with secondary antibody alone were used as negative controls. Images were obtained with a Leica SPE confocal microscope.

\section{Chemotaxis assays}

Transwell chambers with $8 \mu \mathrm{m}$ pore diameter polycarbonate membranes (Corning, New York, NY, USA) were used to measure cell chemotaxis. Sub-confluent cells were trypsinised and 10,000 cells/well were seeded in the upper compartment of the chambers (previously pre-coated with a $10 \mu \mathrm{g} / \mathrm{mL}$ fibronectin solution). The medium used was M199, 1 \% FBS, 1 \% L-glu, 1 \% Pen/Strep, 1 \% Pyr, $22.5 \mu \mathrm{g} / \mathrm{mL}$ heparin. The lower compartment of the wells was occupied by a scaffold disc (PLA, PLA/G5 or PLA/ G5 with CaSR antibodies or EGTA). Cells were allowed to migrate for $48 \mathrm{~h}$ (to allow for the degradation of the glass) and then were fixed in $10 \%$ formalin (Sigma) and stained with DAPI. Nuclei from migrated cells were counted in 4 different random fields of each sample and averaged. Controls denote chambers with no gradient (cell culture medium in upper and lower compartments), while positive control was a $40 \mathrm{ng} / \mathrm{mL}$ VEGF gradient.

\section{Scanning electron microscopy (SEM)}

Cells were fixed after $7 \mathrm{~d}$ growth in the different conditions in $2.5 \%$ glutaraldehyde for $2 \mathrm{~h}$, followed by a post-fixation step with $1 \%$ osmium tetroxide, dehydrated in increasing 
concentrations of ethanol $(50 \%, 70 \%, 90 \%, 96 \%$ and $100 \%$ ), critically point-dried and gold-sputtered.

\section{Collagen I tube formation assay}

Cells were harvested by trypsinisation and seeded at 20,000 cells/well in growth factor free M199 with $1 \%$ FBS, $1 \%$ L-glu, $1 \%$ Pen/Strep, $1 \%$ Pyr and $22.5 \mu \mathrm{g} /$ $\mathrm{mL}$ heparin. After $4 \mathrm{~d}$, phase contrast micrographs were taken. Branching was quantified by counting sprouting tube-like structures longer than $100 \mu \mathrm{m}$ in 4 separate fields in duplicate samples. Cells stimulated with $40 \mathrm{ng} /$ mL VEGF were used as a positive control. For collagen I tube formation, a collagen I solution was diluted in culture media to a final concentration of $1.5 \mathrm{mg} / \mathrm{mL}$ collagen I (BD Bioscience, Franklin Lakes, NJ, USA) with addition of $1 \mathrm{~N}$ $\mathrm{NaOH}$ and $20 \mathrm{mM}$ HEPES. The solution was carefully layered over the cells.

\section{Angiogenesis qRT-PCR array}

RNA was extracted from cells growing for $3 \mathrm{~d}$ in the different conditions (tissue culture polystyrene (TCPS), glass, PLA, PLA/G5) using a RNeasy Minikit (Qiagen, Venlo, Netherlands) following the manufacturer instructions. Reverse transcription of the samples was performed with a $\mathrm{RT}^{2}$ First Strand Kit (SABiosciences, Venlo, Netherlands). $0.5 \mu \mathrm{g}$ cDNA and $\mathrm{RT}^{2}$ qPCR SYBR Green Master Mix (SABiosciences) were used in array plates containing a panel of 86 angiogenesis-related genes, 5 housekeeping control genes, a rat genomic contamination control and RT-controls (Angiogenesis PCR array, PARN024Z, SABiosciences). Amplification was performed with a 10 min $95{ }^{\circ} \mathrm{C}$ activation step followed by 40 cycles at $95^{\circ} \mathrm{C}$ for $15 \mathrm{~s}$ (denaturation) and $1 \mathrm{~min}$ at $60^{\circ} \mathrm{C}$ (extension). Results were log converted, analysed using Euclidean distance and hierarchical clustering and represented as a heat map (Cluster and Java TreeView software). Gene ontology was performed using QuickGO. Only statistically significant results are shown.

\section{VEGF protein quantification}

Endothelial progenitors were seeded either in TCPS, glass or biomaterial at a density of 40,000 cells/well in growth factor and serum-reduced medium (1 \% FBS). For PLA/G5, treatment with blebbistatin or CaSR antibodies was performed as described in "Blebbistatin and CaSR antibody treatments". For 3 d, every 24 h, medium was recovered for VEGF protein quantification (Quantikine Rat VEGF Detection, R\&D Systems, Minneapolis, MN, USA). A standard curve of known VEGF concentrations $(0,31.2,62.5,125,250,500,1,000$ and $2,000 \mathrm{pg} / \mathrm{mL})$ was prepared. Samples were diluted 10 times in assay diluent and incubated for $2 \mathrm{~h}$ on an orbital shaker. Afterwards they were washed and incubated for $1 \mathrm{~h}$ with VEGF conjugate. Following extensive washing, substrate solution was added and incubated for $30 \mathrm{~min}$. Optical density was determined at $450 \mathrm{~nm}$ for each well, including a blank and a negative control. Optical density values were transformed to $\mathrm{pg} /$ $\mathrm{mL}$ using the standard curve values adjusted to a linear regression as recommended by the manufacturer. Results are normalised to cell number (as determined by counting in a haemocytometer after trypsinisation).

\section{VEGFR-2 protein semi-quantification}

Cells seeded at a density of 40,000 cells/wells either in glass, PLA or PLA/G5 scaffolds (untreated or treated with either blebbistatin or CaSR antibodies) for $24 \mathrm{~h}$ were washed with PBS, fixed in $3 \%$ paraformaldehyde, permeabilised with TX-100 and blocked with $6 \%$ BSA for $1 \mathrm{~h}$ at $37^{\circ} \mathrm{C}$. Afterwards, they were incubated overnight at $4{ }^{\circ} \mathrm{C}$ with VEGFR-2 antibodies (Santa Cruz), followed by Alexa 488 secondary antibodies for $1 \mathrm{~h}$ at $37^{\circ} \mathrm{C}$, counterstained with DAPI and mounted in microscope slides for confocal observation (Leica). The microscope laser settings were adjusted for optimal visualisation of the samples. All samples were imaged under the same conditions (laser intensity, objectives, zoom, pinhole size, etc). Pictures were taken in 4 different random fields in each sample. A section of 20 × $20 \mu \mathrm{m}$ was selected and positioned over a cell. The image pixel intensity was then measured with ImageJ software (http://rsbweb.nih.gov/ij). The process was repeated 4 times per field, over a different cell each time. Afterwards the values were averaged and expressed relative to control substrate (glass).

\section{Statistical analysis}

Data are representative of at least 3 independent experiments, except where otherwise noted. Results are expressed as mean \pm S.E.M. Statistical significance was determined by Student's $t$-test ( $p<0.05$, two-tails).

\section{Results}

Material characterisation and calcium releasing properties The composite biomaterial (PLA/G5) consists of a highly porous PLA matrix containing calcium phosphate bioactive glass particles (termed G5 glass, Fig. 1a, b). G5 glass has high controllable biodegradability which results in the liberation of biologically relevant ions to the medium, such as calcium (Navarro et al., 2004). In bulk solution, PLA/G5, but not PLA, releases an amount close to $0.5 \mathrm{mM}$ calcium over a period of $8 \mathrm{~d}$. G5 films also release calcium, although the kinetics are different and depletion of the film can be detected at $4 \mathrm{~d}$ (Fig. 1d). The total porosity of the composite scaffolds is $\sim 95 \%$, with controlled pore size within the $80-210 \mu \mathrm{m}$ range (Table 1 ). Considering previous work with glass-based materials, we speculated that PLA/G5 could possess proangiogenic potential (Day, 2005; Xynos et al., 2000).

\section{PLA/G5 promotes endothelial progenitor cell microcapillary-like tube formation}

In order to test our hypothesis in a relevant setting for future applications, we established an in vitro EPC-biomaterial

Table 1. PLA and PLA/G5 scaffold material properties relevant to cell behaviour.

\begin{tabular}{|l|c|c|}
\hline & PLA & PLA/G5 \\
\hline Porosity $(\%)$ & $92 \pm 2.25$ & $95.1 \pm 1.51$ \\
\hline Pore size $(\boldsymbol{\mu m})$ & $200-500$ & $200-500$ \\
\hline E $(\mathbf{K P a})$ & $74.5 \pm 0.15$ & $120 \pm 0.03$ \\
\hline
\end{tabular}


a
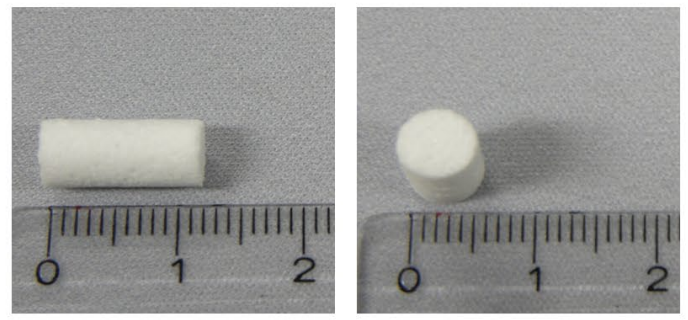

C

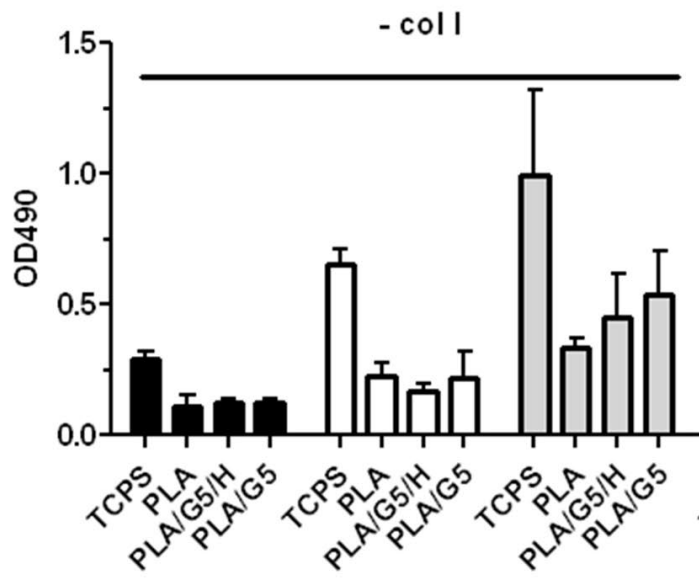

b
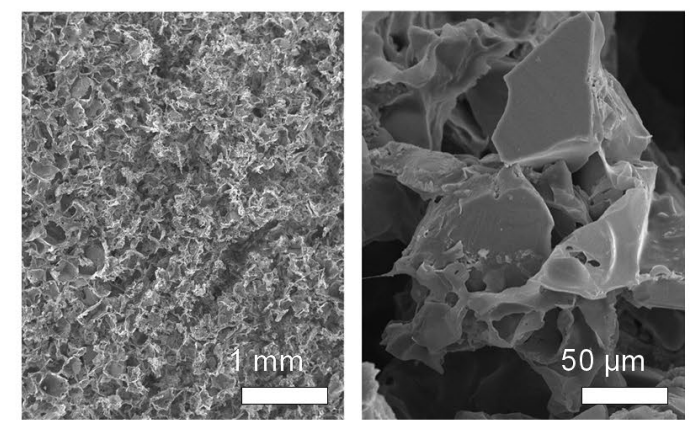

+ coll
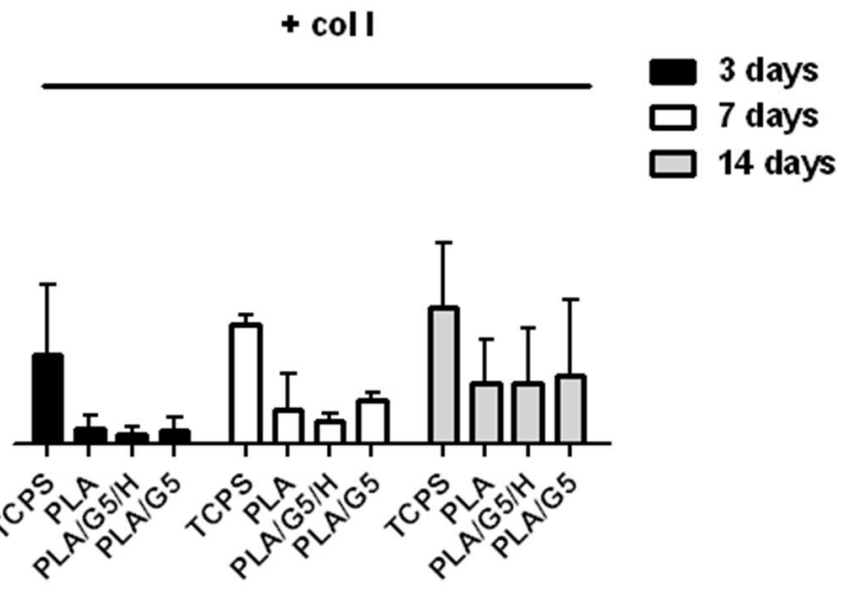

d

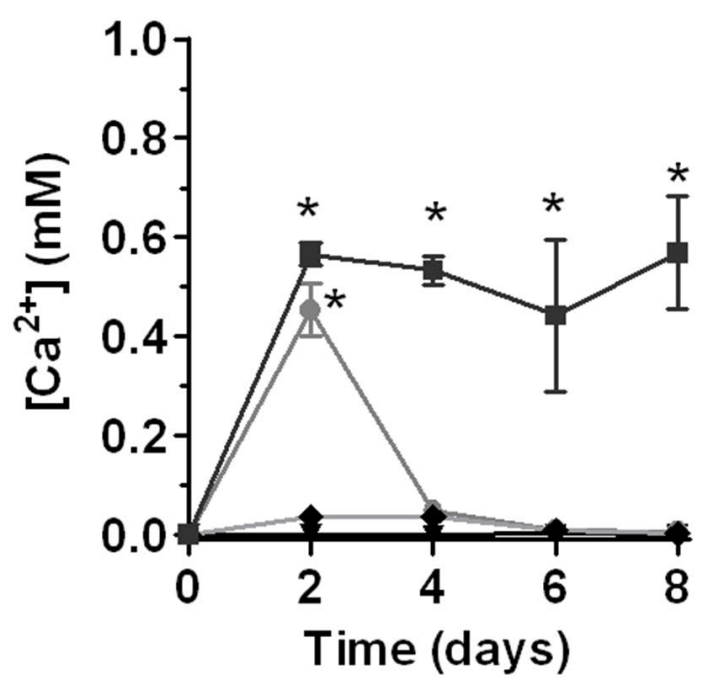

V Ctrl

- G5 film

- PLA

- PLA/G5

Fig. 1. Structural properties, cytotoxicity assay and calcium release of PLA/G5 scaffolds. a) PLA/G5 scaffold side and up views. Scaffolds were $12 \mathrm{~mm}$ in length and $6 \mathrm{~mm}$ in diameter. b) SEM micrographs show microstructure and the position of the glass microparticles in the PLA matrix. c) Cell viability measured by mitochondrial dehydrogenase activity at 3, 7 and $14 \mathrm{~d}$ $(n=4)$. d) Calcium release dynamics of control (medium alone), G5 glass films, PLA and PLA/G5 scaffolds to the medium.

culture system. Bone marrow EPCs were seeded on different substrates: TCPS (negative control), PLA and PLA/G5 scaffolds (glass coverslip controls were also used but no difference was observed in comparison to TCPS, data not shown). TCPS was used as a negative control since EPCs do not form tube-like structures in this material and there are no biochemical signals aside from those in the cell culture medium. An additional experimental condition was created by adding a collagen I matrix to all materials (thus providing a positive proangiogenic environment) to have positive tube-forming conditions. Proliferation was similar in all materials and no cytotoxicity was detected up to $14 \mathrm{~d}$ (Fig. 1c). Collagen I somewhat delayed cell proliferation (Fig. 1c), but this was probably caused by the method of application (it has to be overlaid at $4{ }^{\circ} \mathrm{C}$ ).

Cell adhesion and morphology were followed for 3 d (Fig. 2a) by fluorescent microscopy. EPCs grew to a monolayer on TCPS, with normal spread-out morphology. 
a

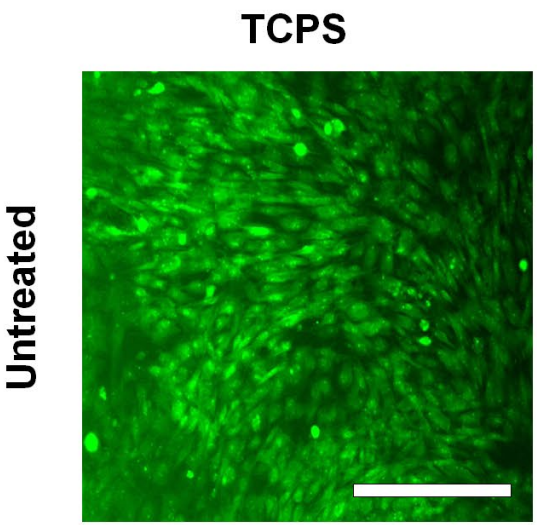

PLA
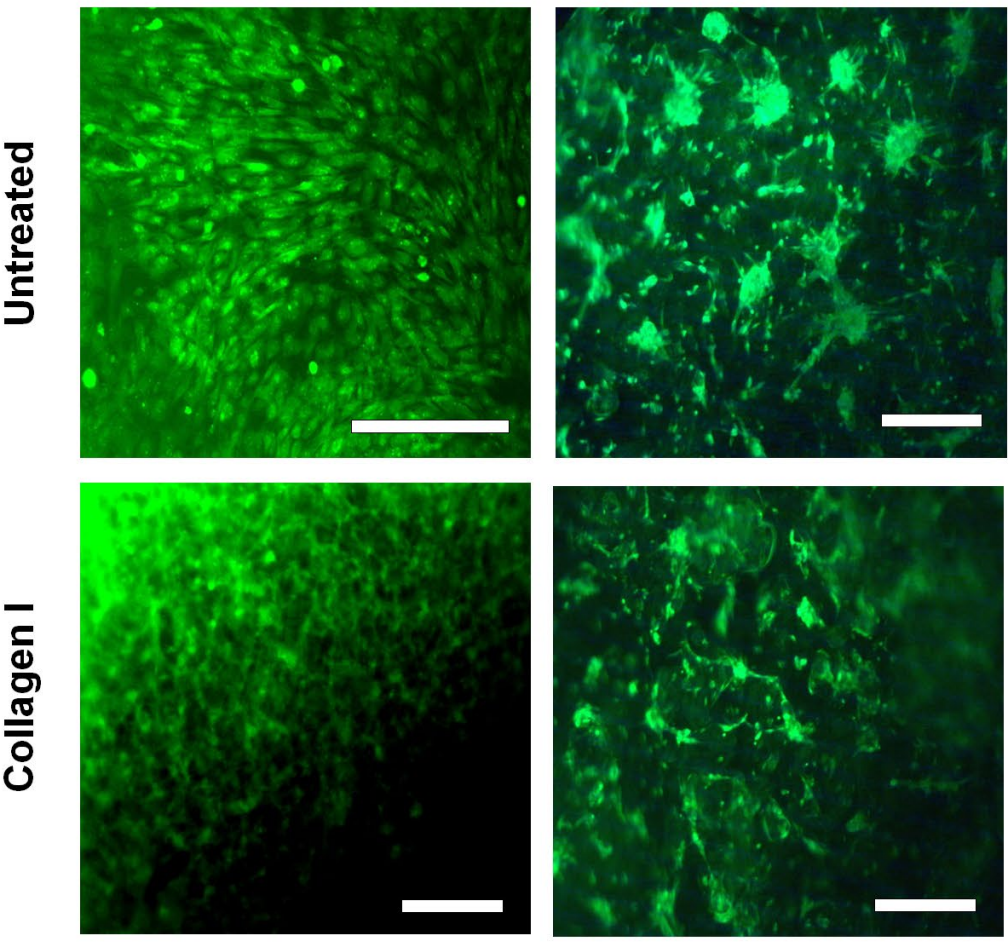

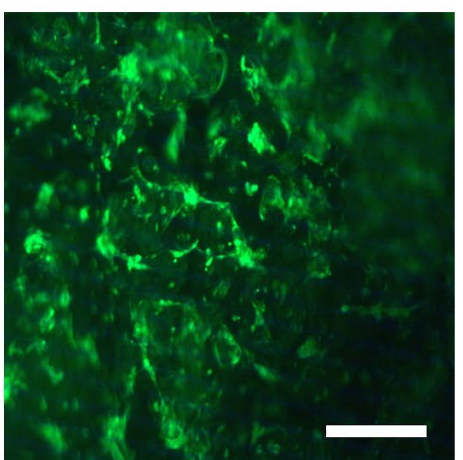

C
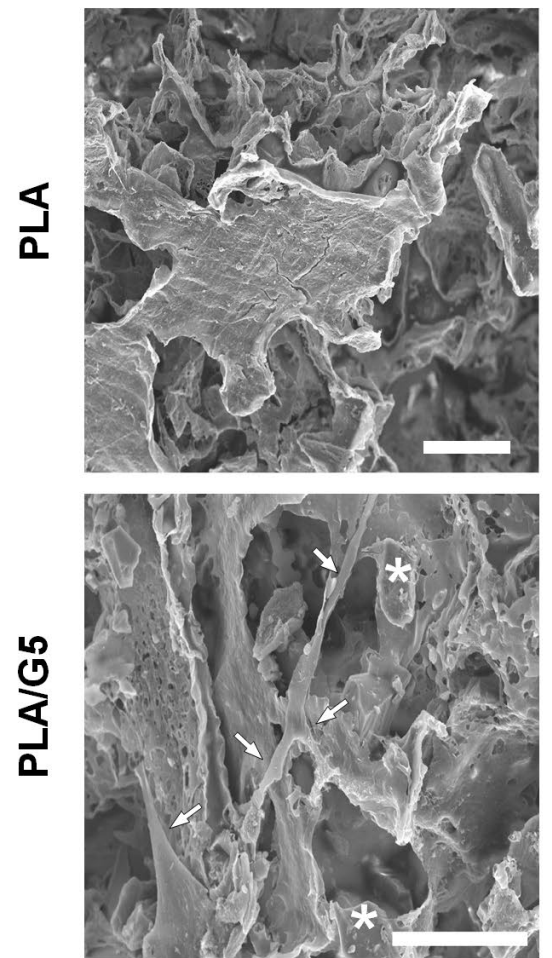

PLA/G5
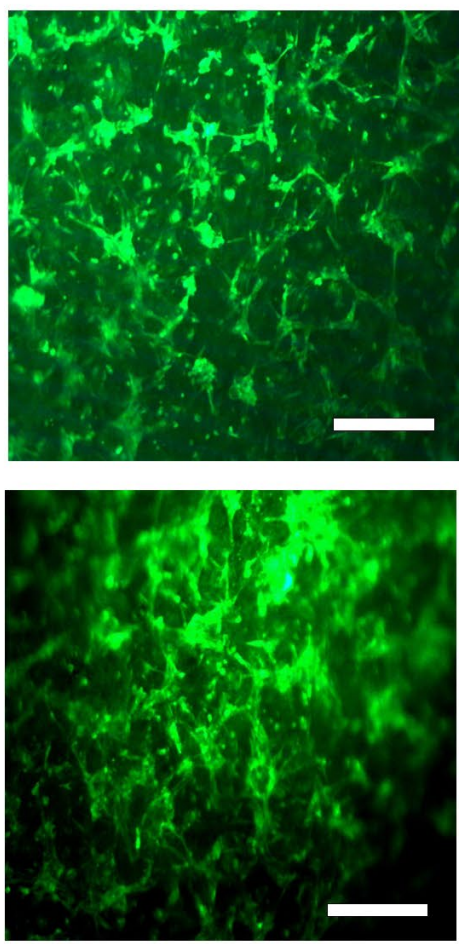

b

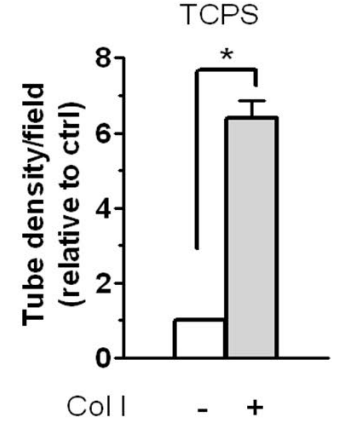

PLA

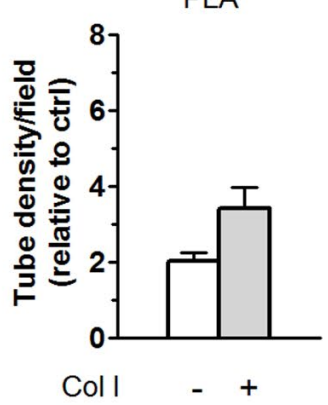

PLA/G5

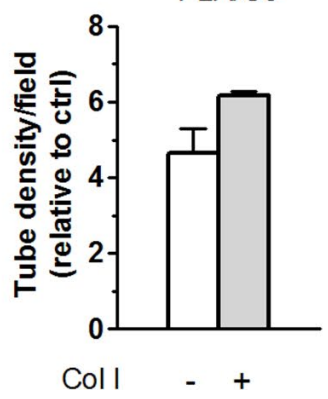

Fig. 2. PLA/G5 promoted in vitro EPC self-organisation into microcapillary-like structures. a) Microcapillary-like tube formation by EPCs seeded in TCPS, PLA or PLA/G5 scaffolds for $3 \mathrm{~d}$ in presence or absence of proangiogenic collagen I gel. Cells were stained with acridine orange $(n=3)$. Scale bar: $200 \mu \mathrm{m}$. b) Quantification of tubule formation. c) SEM micrographs of EPCs in PLA and PLA/G5 scaffolds after $7 \mathrm{~d}$ culture. Scale bar: $50 \mu \mathrm{m}$. Asterisk: G5 glass. Arrows: endothelial progenitor cells. 
a

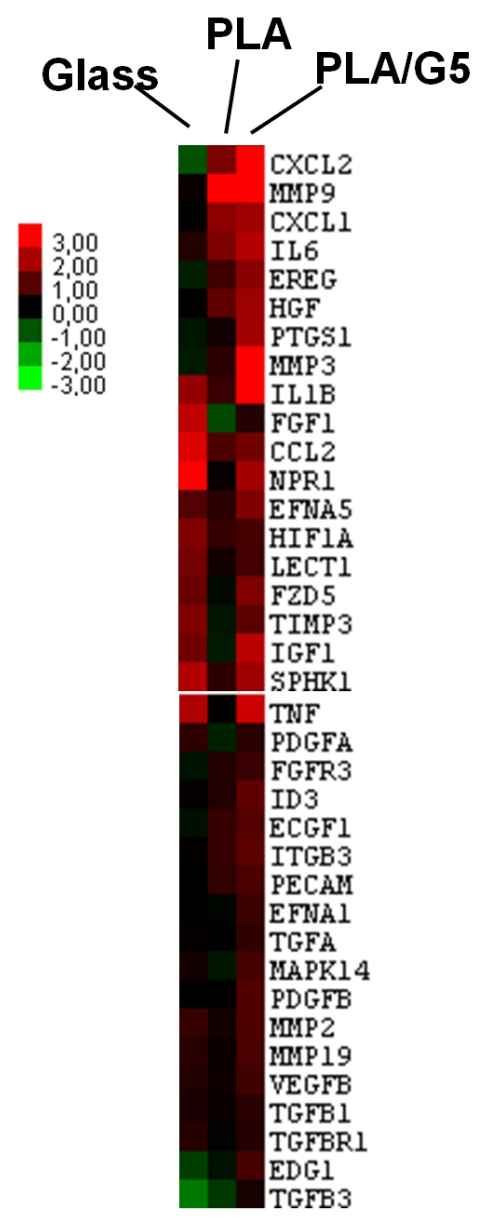

b
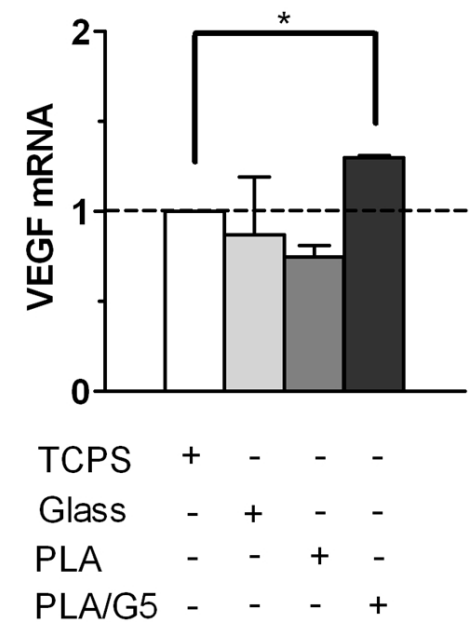

C

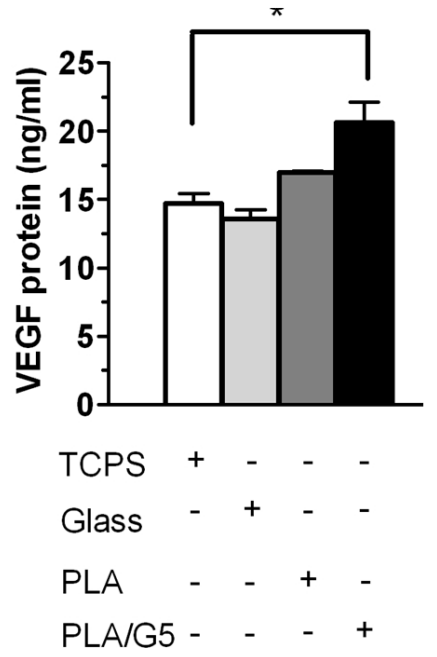

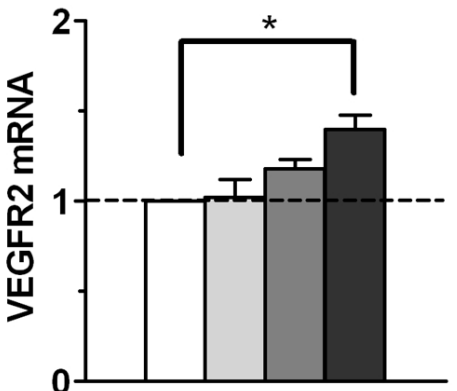

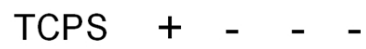

Glass - + - -

PLA - - + -

PLA/G5 - - +

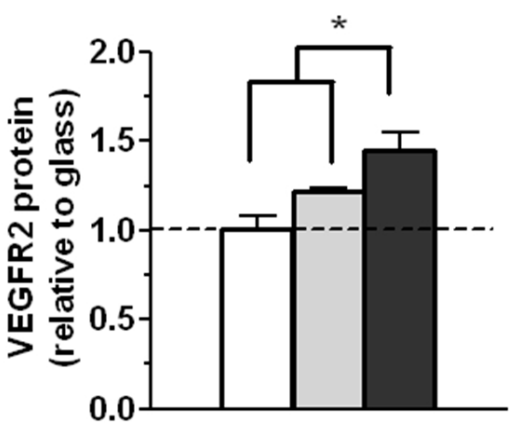

Glass

PLA

PLA/G5 - - +

Fig. 3. PLA/G5-mediated EPC differentiation and proangiogenic cytokine production. a) Real-time RT-PCR changes in angiogenic gene expression profiles in the different conditions. Only significantly up-regulated genes are shown. Results were expressed relative to TCPS-seeded EPCs $(n=4, p<0.05)$. b) Real time RT-PCR for VEGF and VEGFR-2 showed a significant up-regulation when cells were in contact with PLA/G5. Results were expressed relative to TCPS-seeded EPCs $(n=4, p<0.05)$. c) Protein quantification was measured by ELISA (for VEGF) or by immunofluorescent intensity semiquantification after $3 \mathrm{~d}$ culture. VEGFR-2 results are expressed as fold increase over glass $(n=3, p<0.05)$.

PLA induced the aggregation into small round clusters, with occasional sprouting. PLA/G5 presented significantly higher numbers of tube-like structures when compared to TCPS (4.66 \pm 0.63 -fold versus $1 \pm 0.04$-fold) or PLA scaffolds ( $2.03 \pm 0.22$-fold $)$ even in the absence of proangiogenic collagen I gel (Fig. $2 \mathrm{a}, \mathrm{b}, n=4, p<0.05$ ). These structures were not limited to pore-lining cells, but would also develop across pores or penetrate further into the material. As expected, the collagen matrix induced tubulogenesis on TCPS and PLA, and although it also increased EPC tube formation in PLA/G5, the difference was not significant when compared to naked PLA/G5, suggesting that cells already had an active proangiogenic program in motion (Fig. 2a, b). The same trend was observed in 7 and $14 \mathrm{~d}$ cultures (data not shown). SEM analysis provided information on cell interaction with the composite. EPCs seeded on PLA exhibited poor attachment and a tendency to self-contact, forming monolayer-like clusters (Fig. 2c). PLA/G5 induced cells to elongate and to contact each other. In many cases, cells used glass particles as anchorage points (Fig. 2c).

\section{Endothelial differentiation and proangiogenic gene} expression takes place when EPCs are cultured in PLA/G5 by activation of VEGF-VEGFR2 signalling

To confirm that angiogenesis was taking place, gene expression analyses for a panel of endothelial and angiogenic markers was carried out. PLA/G5 induced significant changes in EPC gene expression (43\% of the tested genes were up-regulated), which were further characterised by gene ontology. $44 \%$ of the genes were involved in signalling and endothelial differentiation (such as EphA, IGF1, EDG1, ECGF1, PDGF-A, CD31 and Itga3), $12 \%$ in general proliferation and $7 \%$ in 
a

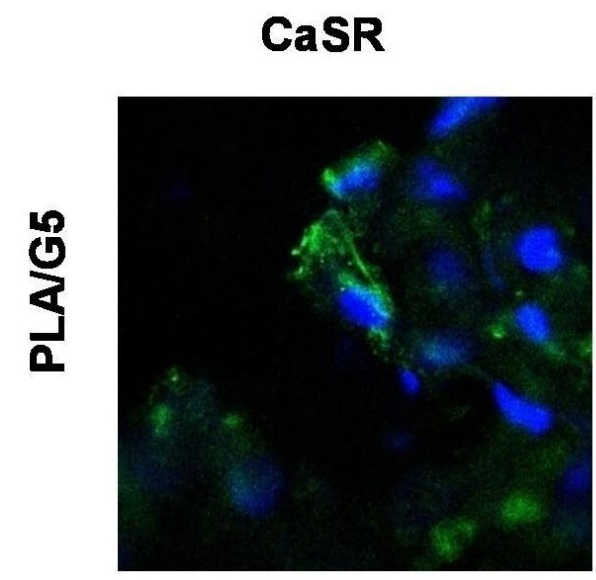

b
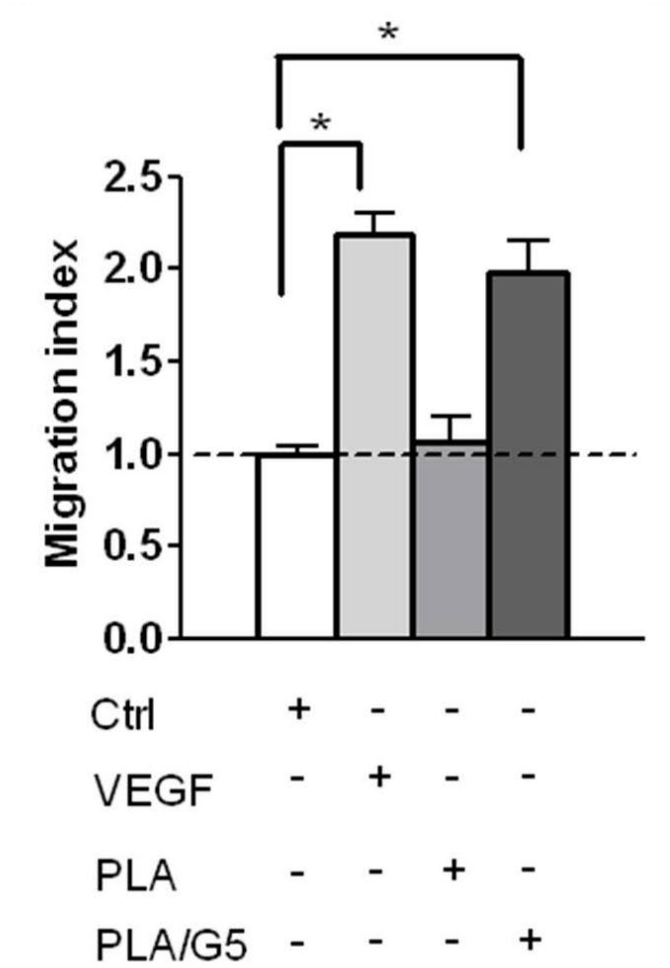

d
PLA

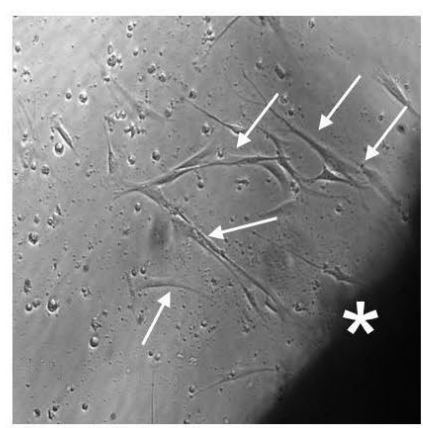

C

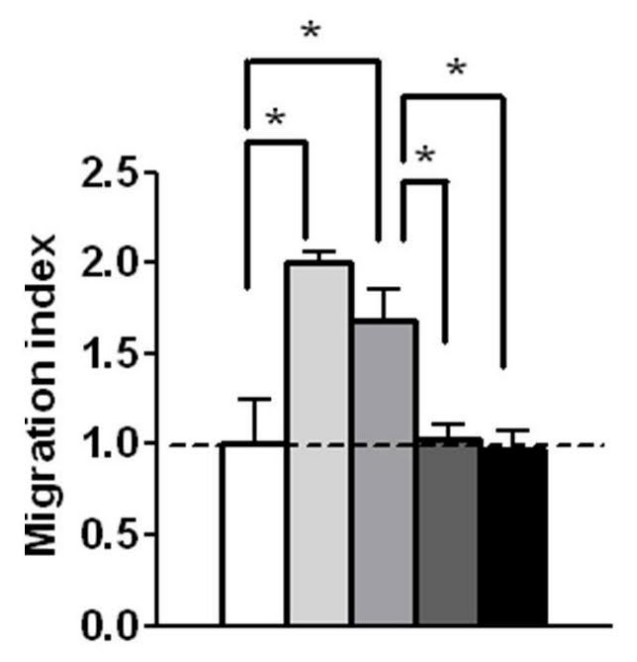

Ctrl

VEGF

$\mathrm{PLA} / \mathrm{G} 5$ - -+++

$\alpha \mathrm{CaSR}$ - - - +

EGTA - - - - +
PLA/G5

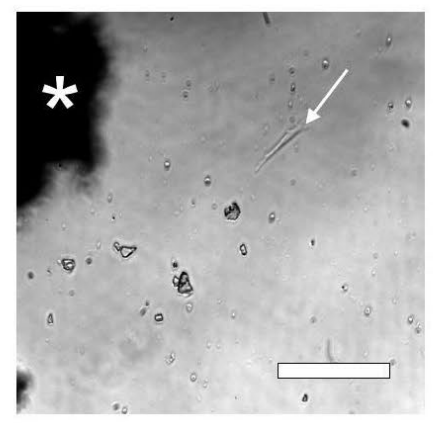

Fig. 4. Biochemical signals carried by PLA/G5 induced chemotaxis in EPCs through activation of the CaSR. a) Immunofluorescent localisation of CaSR in PLA/G5-seeded EPCs. Scale bar: $50 \mu \mathrm{m}$. b) EPCs were chemotactically attracted towards PLA/G5 as shown by Boyden chamber assays. VEGF was used as positive control. Results expressed relative to control migration $(n=4, p<0.05)$. c) PLA/G5mediated EPC chemotaxis and its calcium dependency. Results expressed relative to control migration $(n=3, p<0.05)$. d) Bright field micrographs show that PLA/G5 scaffolds were more attractive to EPCs than their PLA counterparts. Scale bar: $100 \mu \mathrm{m}$. 

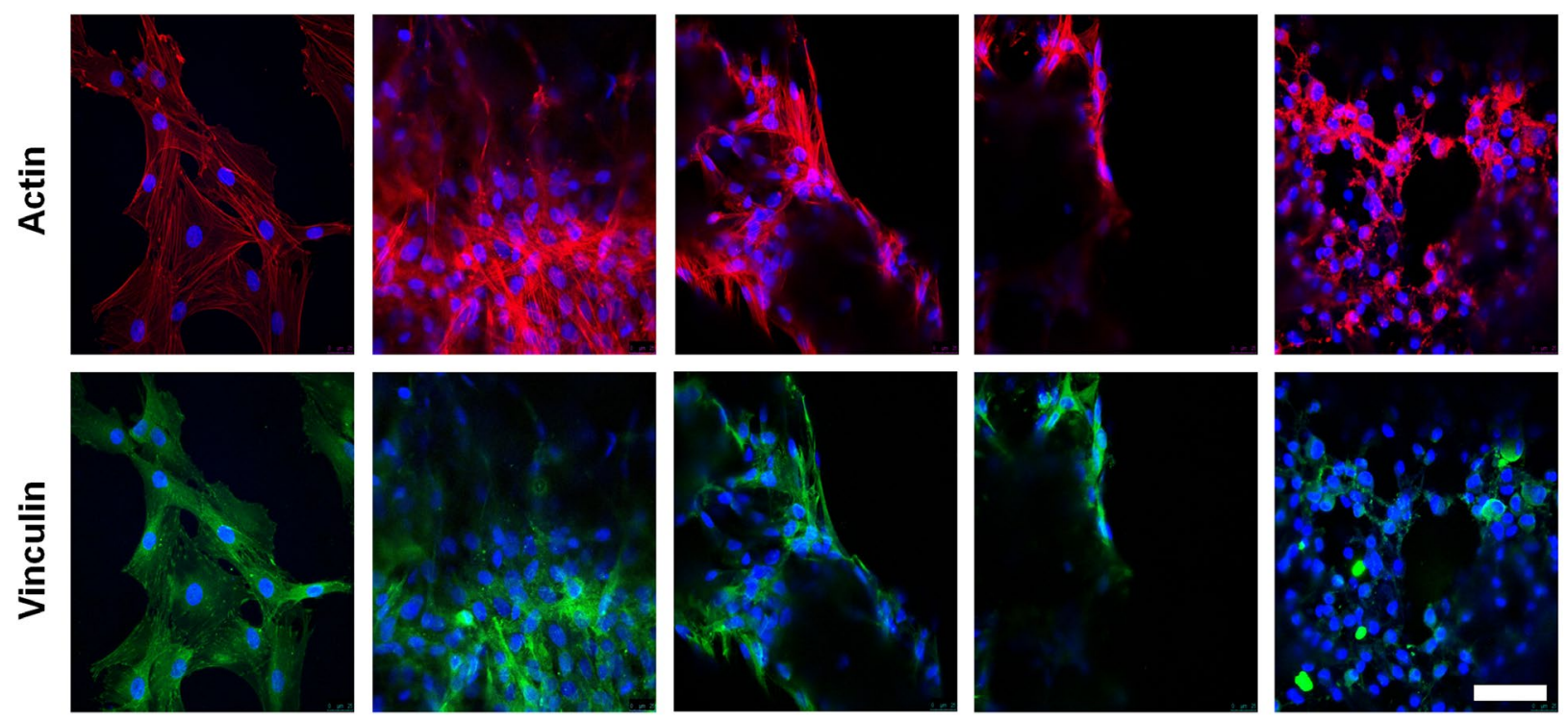

Glass

PLA

PLA/G5

$\alpha \operatorname{CaSR}$

Bleb

Fig. 5. EPC cytoskeletal stress and focal adhesion formation were affected by PLA/G5. Cell morphology and cytoskeletal organisation were evaluated by confocal observation of the actin cytoskeleton and focal adhesions (red: actin, green: vinculin). Cells in glass exhibited high tension and spreading, with focal adhesion formation over the cell periphery. PLA and PLA/G5-seeded cells adopted an elongated morphology with lower tension (actin stress fibres were still visible but less frequent, and vinculin appeared diffuse in the cytosol). Blebbistatin-treated cells lost most of their cytoskeletal organisation. Scale bar: $50 \mu \mathrm{m}$.

extracellular matrix remodelling (Mmp3, Mmp9). This behaviour was not observed in glass or PLA (Fig. 3a), but it was possible to reproduce proangiogenic gene expression on G5 glass films manufactured by sol-gel fabrication. Cells on these films up-regulated CD31 and vWF factor expression significantly, although microscopical evaluation showed no tube formation or evident morphological changes (data not shown).

Given the importance of the VEGF-VEGFR2 signalling axis in vascular development, EPC changes in these two factors were determined after $3 \mathrm{~d}$ in PLA/G5 (Fig. 3b). VEGF and VEGFR-2 mRNA were significantly upregulated when cells were in contact with PLA/G5 (1.3 \pm 0.01 -fold for VEGF and 1.4 \pm 0.08 -fold for VEGFR-2). Glass and PLA induced no significant differences either in $\operatorname{VEGF}(0.87 \pm 0.32$-fold and $0.75 \pm 0.06$-fold, respectively) or VEGFR-2 expression (1.02 \pm 0.1 -fold and $1.18 \pm 0.05$ fold, respectively). Results were expressed relative to TCPS-seeded EPCs $(n=4, p<0.05)$. At the protein level (Fig. 3c), after 3 d culture, EPCs had increased VEGF production in PLA/G5 $(20.64 \pm 1.48 \mathrm{ng} / \mathrm{mL})$ compared to TCPS $(14.73 \pm 0.75 \mathrm{ng} / \mathrm{mL})$, glass $(13.61 \pm 0.62 \mathrm{ng} /$ $\mathrm{mL})$ or PLA $(16.99 \pm 0.12 \mathrm{ng} / \mathrm{mL})$, and also higher levels of VEGFR-2 membrane expression (1.46 \pm 0.09 -fold for PLA/G5, $1 \pm 0.08$-fold for TCPS and $1.22 \pm 0.02$-fold for PLA). VEGFR-2 results were expressed as fold increase over glass $(n=3, p<0.05)$.

\section{Material-mediated calcium release and matrix} stiffness properties are essential for EPC migration and tube formation

G5 glass releases significant amounts of free calcium upon degradation (Fig. 1d), regardless of the fabrication procedure (melting in solvent casting PLA/G5 scaffolds or sol-gel in the case of films). EPCs cultured on PLA/G5 scaffolds expressed CaSR at the cell membrane (Fig. 4a). Previous data show that this receptor is functionally active in EPCs and exerts modulatory effects on differentiation and their angiogenic properties (Aguirre et al., 2010a). We hypothesised that PLA/G5 effects could be, at least in part, mediated by its calcium-releasing properties. CaSRmediated chemotaxis was determined in Boyden chamber assays to examine the EPC migratory response to PLA/ G5 (Fig. 4b). EPCs were chemotactically attracted towards PLA/G5 $(1.98 \pm 0.17)$, but not to PLA $(1.06 \pm 0.14)$. VEGF was used as positive control $(2.19 \pm 0.11)$. PLA/ G5-mediated chemotaxis was completely blocked by antiCaSR $(1.03 \pm 0.09)$ or by removal of extracellular calcium with the calcium chelator EGTA $(0.97 \pm 0.13$, results expressed relative to control migration, $n=3, p<0.05$, Fig. $4 c)$. On a different experimental setting, EPCs seeded in PLA/G5 or PLA scaffolds were placed in plastic dishes and observed for $4 \mathrm{~d}$. A significant amount of cells detached or were actively migrating out of the PLA material; however, they were attracted to PLA/G5 (very few cells were seen leaving the biomaterial, Fig. 4d). 
a

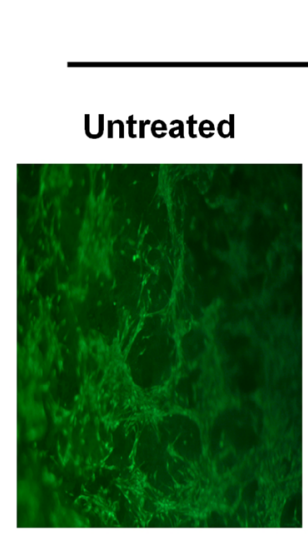

C

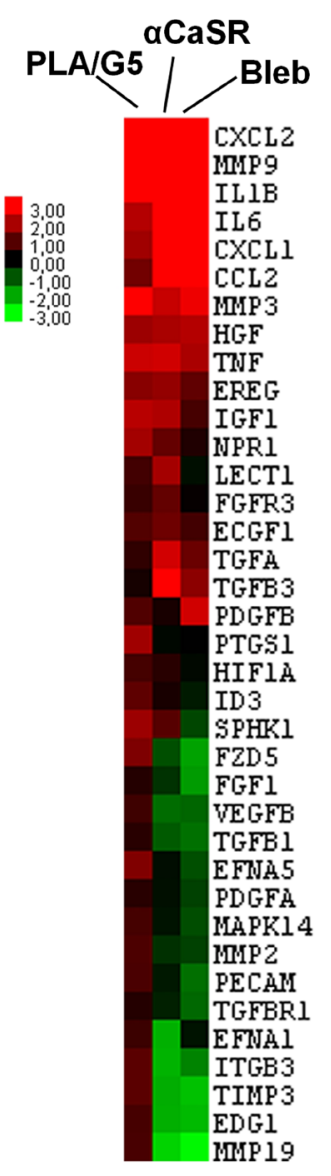

b

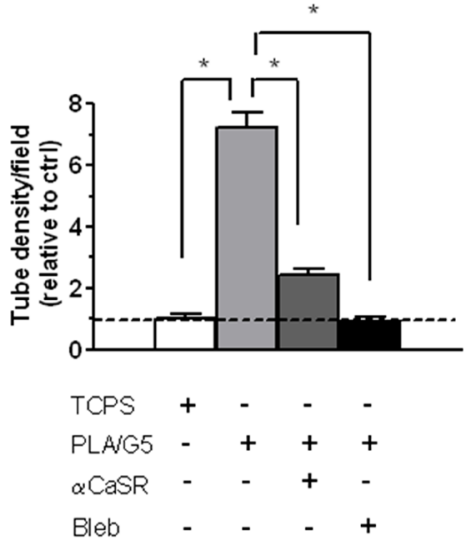

d
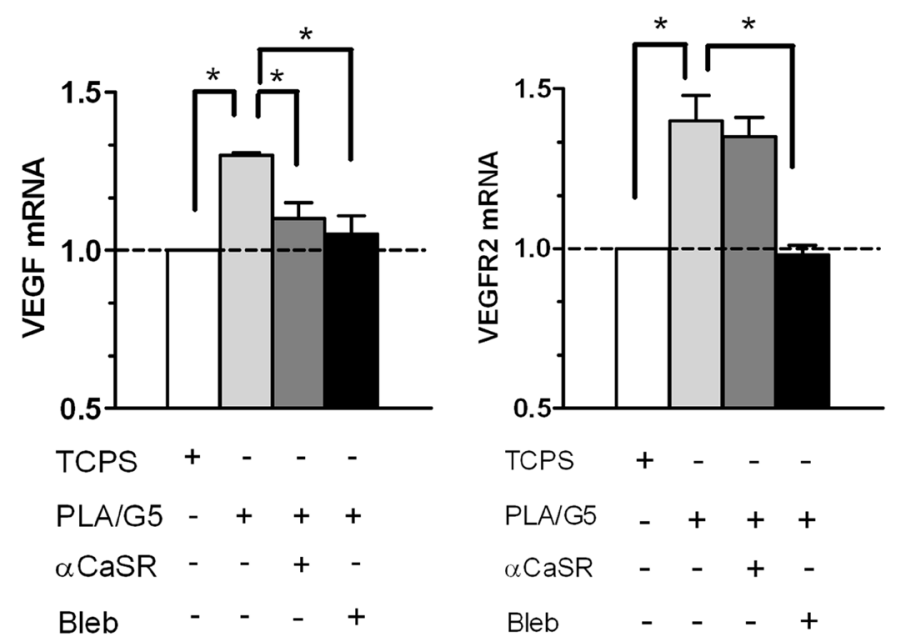

PLAVG5 - + + +

$\alpha$ CaSR - $\quad+-$

Bleb

e
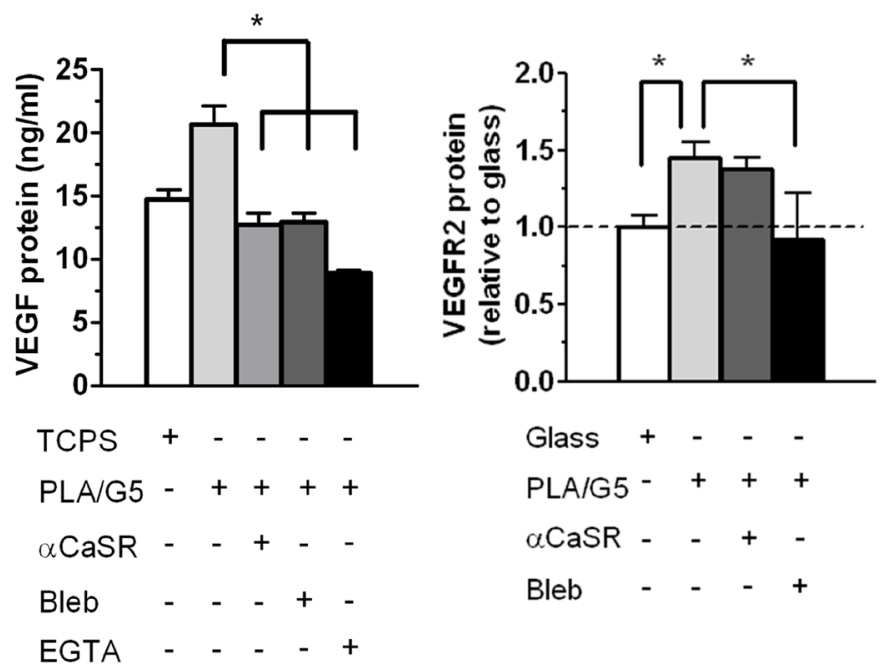

Fig. 6. PLA/G5-mediated EPC proangiogenic behaviour can be eliminated by inhibition of either calcium-sensing or matrix stiffness-mediated mechanotransduction. a) Fluorescent micrographs showing EPC tube formation in PLA/G5, PLA/G5 treated with CaSR blocking antibodies, or inhibition of NMII contraction with blebbistatin. Scale bar: $200 \mu \mathrm{m}$. b) Quantification of tube formation in PLA/G5-seeded cells before treatment and after antibody or blebbistatin treatment. Results expressed as fold increase over cells in TCPS $(n=3, p<0.05)$. c) Real time RT-PCR array experiments indicated a strong impairing of the differentiation process when CaSR antibodies or blebbistatin were applied. Results expressed relative to TCPS-seeded EPCs $(n=4, p<0.05)$. d) Quantification of VEGF and VEGFR-2 expression before and after treatment with CaSR blocking antibodies or blebbistatin. Results expressed relative to cells growing on TCPS $(n=3, p<0.05)$. e) Protein synthesis of VEGF or VEGFR-2 measured by ELISA (for VEGF) or intensity semi-quantification (VEGFR-2). Protein results expressed relative to cells growing on glass $(n=3, p<0.05)$. 
a

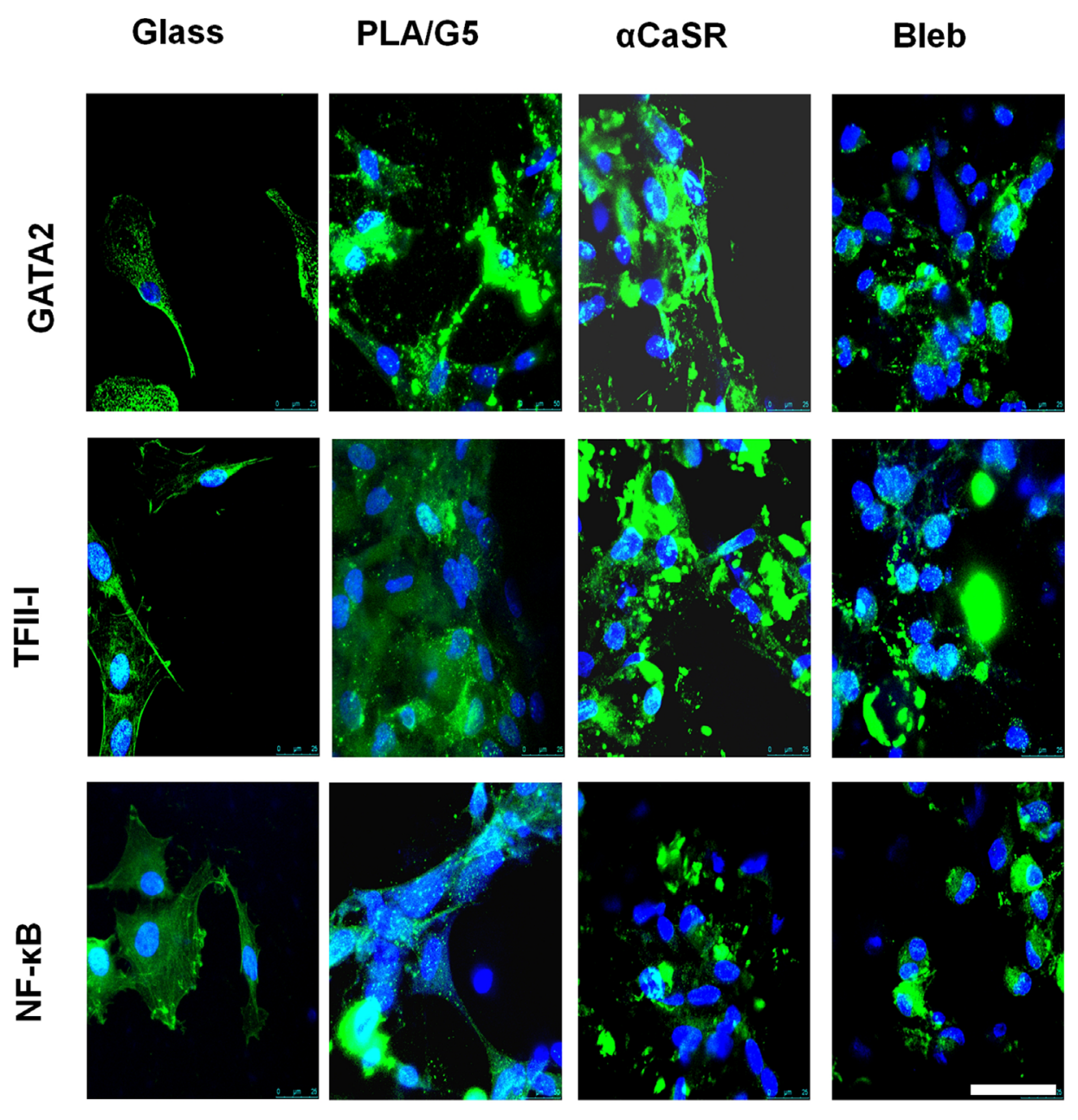

b
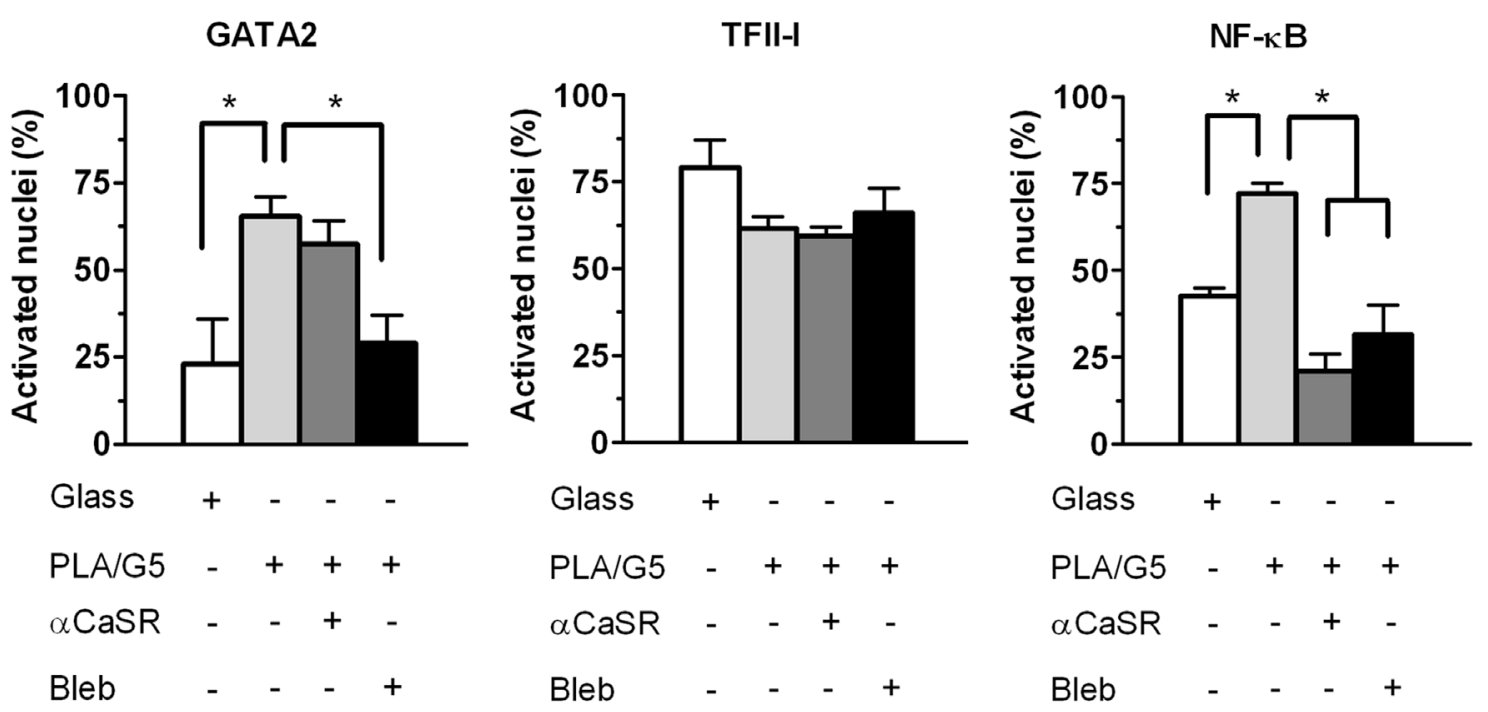

Fig. 7. Biomaterial effects are mediated by nuclear translocation of transcription factors associated to the CaSR and mechanosensing. a) Nuclear presence of GATA2, TFII-I and NF-kB transcription factors was determined by confocal microscopy on EPCs growing on glass, PLA/G5 or PLA/G5 with one of the inhibitors ( $\alpha$ CaSR, blebbistatin) after $24 \mathrm{~h}$ incubation. b) Quantification of activated cells for each transcription factor. Results expressed as percentage of cells showing activated nuclei $(n=4, p<0.05)$. 
We studied cell morphology and focal adhesion formation at $24 \mathrm{~h}$ by confocal microscopy. It revealed that both PLA/G5 and PLA induced lower levels of actin organisation and diffuse vinculin staining in focal adhesion formation when compared to glass, indicating a different mechanical state. Only EPCs seeded on PLA/G5 exhibited the elongated morphology that precedes tube formation, suggesting the involvement of another factor which was not present in PLA scaffolds (Fig. 5). Treatment with antiCaSR of cells seeded on PLA/G5 had no immediate effect on cytoskeletal organisation or elongated morphology, but inhibition of actomyosin contraction with blebbistatin strongly disrupted the development of elongated cells, again indicating a contribution of mechanosensing to the process of EPC tube formation (Fig. 5). Blebbistatin, at the concentration employed $(20 \mu \mathrm{M})$, did not exert negative effects on cell proliferation or chemotaxis under any of the conditions (data not shown).

\section{PLA/G5-mediated gene expression changes are strongly dependent on extracellular calcium and matrix stiffness}

We tested if addition of either anti-CaSR or blebbistatin could abolish PLA/G5-mediated tube formation after $3 \mathrm{~d}$ (Fig. 6a, b). Quantification of tube formation in PLA/G5seeded cells before treatment (7.25 \pm 0.53 -fold) and after antibody ( $2.44 \pm 0.20$-fold) or blebbistatin treatment ( 0.85 \pm 0.19 -fold) showed significant differences when any of these signal transduction pathways were blocked $(n=3$, $p<0.05$ ). Blockade of the CaSR resulted in a significant disorganisation characterised by a more random cell distribution throughout the material, but morphologically normal cells. Blebbistatin produced cell rounding, but did not affect attachment or proliferation. Any of the two treatments resulted in marked decrease in tube formation (Fig. 6a, b). When both treatments were applied together cell death increased and adhesion to the biomaterial dramatically decreased, so no further tests were carried out for that condition (data not shown).

It was expected that proangiogenic gene expression changes induced by PLA/G5 would be reverted by treatment with anti-CaSR or blebbistatin (Fig. 6c). Application of CaSR blocking antibodies or blebbistatin led to important down-regulation of the pathways activated by PLA/G5 (54\% genes inhibited by anti-CaSR and $64 \%$ by blebbistatin), confirming that CaSR-mediated signalling and mechanosensing played major roles in PLA/G5-mediated EPC proangiogenic differentiation. We determined before that VEGF and VEGFR-2 were important actors in the PLA/G5-mediated cell response. To clarify if VEGF and VEGFR2 up-regulation were CaSR and/or blebbistatin-sensitive, we treated PLA/G5seeded cells with them and measured VEGF and VEFGR2 expression and synthesis (Fig. 6d, e). PLA/G5-induced VEGF up-regulation $(1.3 \pm 0.01$-fold $)$ was significantly reduced by treatment with anti-CaSR $(1.10 \pm 0.05$-fold $)$ or blebbistatin (1.05 \pm 0.06 -fold). VEGFR-2 transcription $(1.40 \pm 0.08$-fold $)$ was affected by blebbistatin $(0.98$ \pm 0.03 -fold $)$, but not by anti-CaSR $(1.35 \pm 0.06$-fold, $n=3$, $p<0.05)$. Protein amount confirmed mRNA results. PLA/
G5-induced VEGF protein production $(20.64 \pm 1.48 \mathrm{ng} / \mathrm{mL}$ versus $14.73 \pm 0.75 \mathrm{ng} / \mathrm{mL}$ for TCPS) was abolished by anti-CaSR $(12.73 \pm 0.91 \mathrm{ng} / \mathrm{mL})$, EGTA $(8.89 \pm 0.19 \mathrm{ng} /$ $\mathrm{mL})$ and blebbistatin $(12.93 \pm 0.72 \mathrm{ng} / \mathrm{mL})$. In the case of PLA/G5-induced VEGFR-2 synthesis ( $1.46 \pm 0.08$-fold), the process was inhibited by blebbistatin $(0.93 \pm 0.24$-fold $)$ but largely unaffected by anti-CaSR $(1.38 \pm 0.06$-fold, $n=3, p<0.05)$.

\section{EPC differentiation is promoted by NF-кB and GATA2 transcription factor activation through the calcium-sensing receptor and non-muscle myosin II} Transcription factors regulate gene expression changes. NF-kB, GATA2 and TFII-I have been involved in endothelial differentiation and mechanosensing. Nuclear translocation of these factors was observed in EPCs that had been in contact with PLA/G5 for $24 \mathrm{~h}$ (Fig. 7a, b). Levels of GATA2 in the nucleus were higher in PLA/G5seeded cells ( $65.5 \pm 5 \%$ activated cells) compared to glass $(23 \pm 13 \%)$. This activation was significantly reduced when cells were treated with blebbistatin $(29 \pm 8 \%)$, but it was left unaffected by anti-CaSR antibodies $(57.5 \pm 6.5 \%)$. Although TFII-I levels in the nucleus of PLA/G5-treated cells were lower, no significant differences were detected in any condition (glass: $79 \pm 8 \%$; PLA/G5: $61.5 \pm 3.5 \%$; anti-CaSR: $59.5 \pm 2.5 \%$; blebbistatin: $66 \pm 7 \%$ ). NF-кB translocation was significantly increased in PLA/G5seeded cells $(72 \pm 3 \%)$ compared to glass $(42.5 \pm 2.5 \%)$. The process was suppressed by cell treatment with either anti-CaSR $(21 \pm 5 \%)$ or blebbistatin $(31.5 \pm 8.5 \%)$.

\section{Discussion}

The need for more sophisticated biomaterials which are able to induce specific tissue responses with minimal side effects has pushed the boundaries of materials science to new levels of sophistication (Mooney and Vandenburgh, 2008). Despite on-going efforts, implants frequently fail to meet this goal. In many cases this is due to a lack of understanding of the biological processes involved, including the interactions at the cell-biomaterial interface. In this study we have employed a composite biomaterial for bone tissue engineering applications based on calcium phosphate glass and PLA (PLA/G5). Both PLA and calcium phosphate are approved for use in humans and present a good resorption rate. In previous studies, it has been determined that the material performs acceptably in vivo, suggesting glass bioactivity, but unexpectedly, it also induced significant osteon formation (Sanzana et al., 2008). The relationship between osteons and bone vascularisation is well-known, so we hypothesised that the material could have vascularising properties (Kanczler and Oreffo, 2008). An in vitro progenitor cell model of angiogenesis was developed to this end, which could also be employed to clarify the on-going biological mechanisms, so that these data could be extrapolated for future biomaterials design. Endothelial progenitor cells (EPCs) were ideal for this purpose since their role in vascularisation has been extensively characterised (Asahara et al., 1997; Larrivée and Karsan, 2007; Takahashi et al., 1999). 
EPCs obtained from bone marrow were seeded on PLA/G5 three-dimensional discs and the effects on cell morphology, proliferation and differentiation were studied. We found that PLA/G5 did not affect cell proliferation (Fig. 1c), but could induce morphological changes leading to microcapillary-like tube formation as early as $3 \mathrm{~d}$ (Fig. 2a, $\mathrm{b}, \mathrm{c})$. This was followed by consistent broad up-regulation of proangiogenic genes and endothelial markers (Fig. 3a). When analysed by gene ontology, it could be established that the majority of these genes were either involved in proliferation, signalling or differentiation, with a smaller number committed to chemotaxis, matrix proteolysis and cell adhesion. These findings fitted well with the other previous observations. Of special importance, the potent proangiogenic mediator proteins VEGF and VEGFR-2 (Fig. 3b, c) were also up-regulated, although increases at the mRNA level were modest; protein synthesis levels for VEGF and VEGFR-2 indicated a $40 \%$ and $46 \%$ induction, respectively. When these changes were taken into consideration combined with the other up-regulated proangiogenic markers and cytokines (Fig. 3a), they suggested a solid proangiogenic profile. A possible explanation for this system involves the development over time of a mixed cell population with different lineages (cells producing VEGF and cells expressing VEGFR2). This is in agreement with other authors' findings, which indicate that EPCs are an heterogeneous population of cells related to the vascular lineage (Asahara et al., 1997). VEGF is a critical growth factor necessary for blood vessel formation, both in the adult and the developing embryo (Holmes et al., 2007; Nomi et al., 2002). It signals through its tyrosine kinase receptor, VEGFR-2, activating a wide array of responses (chemotaxis, survival and proliferation, cytoskeletal rearrangement) (Holmes et $a l ., 2007)$. In our setting, the finding that both VEGF and VEGFR-2 experienced a significant increase offered a possible explanation for the PLA/G5 effects, since it would create a positive, proangiogenic signalling feedback loop. However, we cannot exclude that other proangiogenic pathways were involved (and as a matter of fact, several other angiocrines, such as angiopoietin- 1 and 2 were also up-regulated), although our results suggested that VEGF signalling was one of the main driving forces behind PLA/ G5 effects.

Previous studies have shown that glass-based materials such as Bioglass can induce proangiogenic cytokine production in fibroblasts and thus angiogenesis indirectly, but no data on endothelial progenitors was available (Day, 2005). The mechanism of action for Bioglass remains largely unexplained, although it likely involves bioactive ion release (Xynos et al., 2000; Xynos et al., 2001). In our case, the setting was more complex since the biomaterial was a composite formed by an inert matrix (PLA) and the calcium phosphate bioactive glass. We determined that the glass dissolves releasing biologically relevant amounts of calcium, up to $0.6 \mathrm{mM}$ in bulk solution (Fig. 1), which was in agreement with previous results (Navarro et al., 2004). Biologically, extracellular calcium plays an important role in proliferation, chemotaxis and differentiation through a membrane-bound $G$ proteincoupled receptor named calcium-sensing receptor (CaSR)
(Brown and MacLeod, 2001). Furthermore, calcium can be present at high concentrations in the extracellular fluids of tissues undergoing remodelling, such as healing bone (Silver et al., 1988). Recently, we described a role for this receptor in EPC maturation and chemotaxis, thus offering a partially satisfactory biochemical explanation for the results observed with PLA/G5 (Aguirre et al., 2010a). However, and although PLA is chemically inert, it contributes to the cell microenvironment by providing a certain matrix stiffness which, joined to the high porosity and G5 glass, can be relevant for cell differentiation through mechanosensation.

In recent years, there has been a growing interest in the mechanical properties of the extracellular matrix (Engler et al., 2006). In vivo, cells are embedded in a threedimensional, tissue-specific matrix with defined stiffness properties which presents information to the cells in the form of mechanical stress. Recent experiments have shown that 2D surfaces affect differentiation of stem cells (Engler et al., 2006; Mammoto et al., 2008). Other studies suggest that the effects are stronger and more efficiently transmitted in 3D gels (Byfield et al., 2009). In our biomaterial, cells are initially exposed to a 2D environment with topographical features which likely evolves into a 3D setting over time (as extracellular matrix deposition takes place). The role of matrix stiffness in PLA/G5 was foreseen when the contact with the biomaterial yielded significant morphological changes in EPCs which could not be related to topography, since it was roughly equivalent for PLA and PLA/G5 (Fig. 5). PLA/G5 macroscopic stiffness had been determined to be approximately $120 \mathrm{kPa}$ (Table 1) (Navarro et al., 2004). We speculated that the material structure allowed cells to sense a real stiffness closer to that of PLA $(\sim 70 \mathrm{kPa})$, since G5 glass particles are embedded and suspended in the PLA matrix, and thus forces exerted over G5 glass particles are transmitted through deformation. In this setting, the stiffness sensed by cells would be closer to that of osteoid (30-100 $\mathrm{kPa}$, depending on the maturation stage) (Engler et al., 2006) and would thus support the hypothesis that PLA/G5 mimics osteoid to a certain extent. Furthermore, mathematical modelling and simulations showed that at the microscopic scale, PLA/G5 stiffness was closer to $25-40 \mathrm{kPa}$ when microstructure and pore architecture was included in the calculations (unpublished observations by Prof. D. Lacroix), a number which is very close to the biological stiffness of osteoid. Osteoid is also a potent proangiogenic environment that collaborates in bone vascularisation (Kanczler and Oreffo, 2008). Also, mechanosensation plays a relevant role in endothelial cell tube formation. We observed that matrix stiffness was somehow affecting EPC differentiation because cell morphology and mechanical state (that is, the tension the cells feel and exert in relation to the extracellular matrix) were radically different between tissue culture glass and PLA/G5 culture conditions (Fig. 5).

We hypothesised that if calcium and matrix stiffness were collaborating to create a proangiogenic microenvironment, blockade or inhibition of any, or both, should result in reduced EPC proangiogenic behaviour when in contact with PLA/G5. To test this hypothesis, two different treatments were used on PLA/G5 seeded 


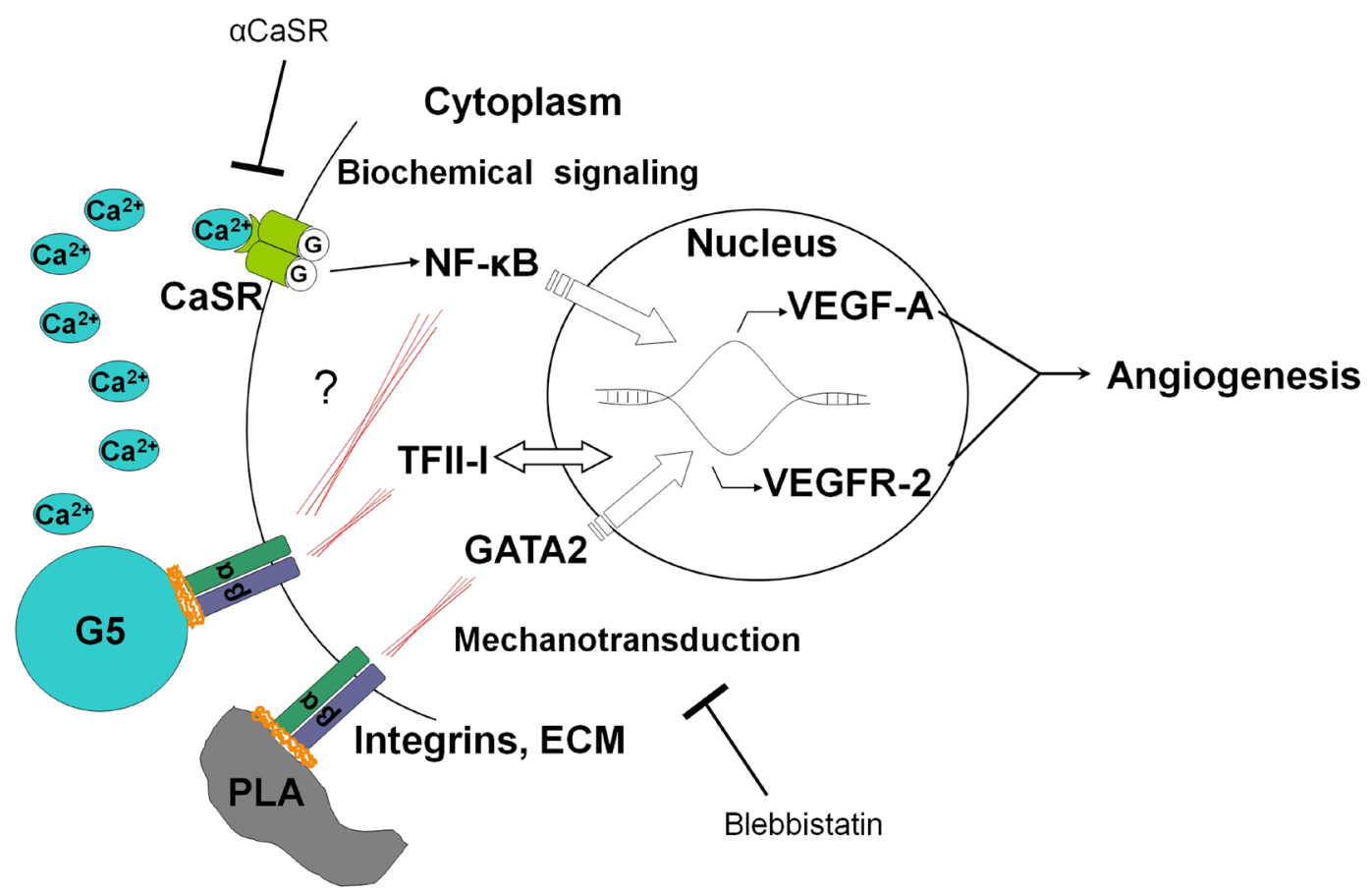

Fig. 8. Schematic model summarising the effects and underlying mechanisms of EPC activation by PLA/G5. Cells receive information from the material through calcium released by the bioactive G5 glass. This calcium activates the $\mathrm{G}$ protein-coupled receptor CaSR. At some point, signalling through the CaSR provokes nuclear translocation of NF-kB that results in increased VEGF-A transcription leading to angiogenesis (an unexplored pathway depending on mechanotransduction is also possible). On the other hand, mechanical signals pertaining to the material stiffness, which in biological terms is similar to that of osteoid, activate transcription factors affecting differentiation (GATA2, NF-kB). The result is the up-regulation of VEGFR-2 transcription and protein synthesis leading to angiogenesis. Thus, biochemical activation and mechanical signalling synergistically promote self-organisation, angiogenesis and differentiation in EPCs.

cells. On one hand, calcium signalling was abolished with anti-CaSR specific blocking antibodies. On the other hand, mechanosensing was inhibited by preventing actomyosin contraction. For this purpose blebbistatin, a specific nonmuscle myosin II inhibitor, was used (Engler et al., 2006). Blebbistatin can cause a number of secondary effects on cells, depending on dose and cell type (Goeckeler et al., 2008; Liu et al., 2010; Wang et al., 2008). We characterised the EPC response to blebbistatin to make sure that the effects observed were not the consequence of toxicity (data not shown). Low blebbistatin concentrations $(20 \mu \mathrm{M})$ with no side effects were employed in all subsequent experiments, reasoning that it was not necessary to completely shut down mechanosensation to observe the inhibitory effects over PLA/G5-mediated proangiogenic activation. Abolishing calcium signalling was sufficient to drastically reduce VEGF production, while blocking mechanosensation affected both VEGF and VEGFR-2 production. Any of the two treatments would cause a dramatic reduction in tube formation and proangiogenic differentiation mediated by PLA/G5, supporting the notion observed before: that a VEGF/VEGFR-2 feedback loop was necessary for sustained PLA/G5 effects (Fig. 6).

Global gene expression changes as those seen in the case of EPCs cultured on PLA/G5 are usually mediated by master regulators such as transcription factors. Experiments were performed to check the potential role of GATA2, TFII-I and NF-кB in PLA/G5-mediated effects, since they have been shown to be involved in angiogenesis through the CaSR (Hammond et al., 2007; Martin et al., 2009) and mechanosensing by regulating VEGF and VEGFR-2 expression (Mammoto et al., 2009). If active, both the CaSR and mechano-sensation can activate complex downstream signalling that results in transcription factor nuclear translocation (Fig. 6, Engler et al., 2006; Mammoto et al., 2008; Spencer et al., 2010). It has been shown that CaSR can affect NF-кB through a PLC (phospholipase C)-dependent pathway in osteoclasts, where local extracellular calcium regulates bone resorption (Mentaverri et al., 2006) and also in endothelial cells (Martin et al., 2009). Among other numerous effects, NFKB regulates VEGF transcription (Martin et al., 2009). We could establish that NF-KB translocation and VEGF production were calcium-sensitive (Fig. 5d, e and Fig. 6). In other publications, authors linked matrix stiffness to nuclear translocation of GATA2 (a fundamental transcription factor in haemangioblastic development (Lugus et al., 2007)) and TFII-I through mechanosensing in endothelial cells (Mammoto et al., 2009). In our setting, GATA2, but not TFII-I, was blebbistatin-sensitive, as well as VEGF and VEGFR-2 synthesis, supporting previous data and offering new insights into the mechanism of action of mechanosensation in endothelial progenitors (Fig. 7). 
Calcium is an important modulator of cell activities and can be considered a drug for biological purposes. The results presented herein suggest that the combination of a precise set of material properties can efficiently elicit controlled cellular responses of interest for tissue engineering and biomaterials science. It would be a mistake to think that calcium alone can induce specific responses (such as growth factors) in many different cell types. Its properties should be exploited in combination with the appropriate set of growth factors/morphogens. However, calcium can probably induce, at least partially, a specific response in cell types intimately linked to calcium homeostasis in calcium-rich tissues (e.g. bone or bone marrow). In our particular case of interest (bone tissue engineering and musculoskeletal repair), it is exciting to think that the in vivo performance of certain biomaterials and their clinical relevance could be boosted by careful addition of calcium and tailored tissue-like mechanical properties, possibly combined with adequate growth factors.

Summarising, PLA/G5 was able to promote EPC angiogenesis by partially mimicking properties of the physiological bone healing microenvironment. Activation of the angiogenic program was carried out by two independent, but related, signalling pathways, one depending on biomaterial-released extracellular calcium and another relying on mechanotransduction. This model is represented and explained in detail in Fig. 8. We did not rule out the involvement of other proangiogenic factors up-regulated in our experiments, but could determine that VEGF/VEGFR-2 is one of the main driving forces behind the effects of the biomaterial.

\section{Conclusions}

We have developed a smart composite biomaterial exerting proangiogenic and chemotactic properties on EPCs by mimicking some qualities of the healing bone matrix microenvironment. To the extent of our knowledge, this is the first time that a composite containing a bioactive, biodegradable glass has been proven to be directly involved in angiogenesis and differentiation of endothelial progenitors. The main advantages of this approach (when compared to others such as protein immobilisation or growth factor release) are the simplicity of material fabrication, low cost and off-theshelf availability, making it a very attractive strategy for clinical applications involving musculoskeletal repair. Future work will involve the development of new, more practical, fabrication techniques, as well as variations of the glass composition (to tune calcium release) that will have to be tested in vitro and in vivo. Moreover, our work integrated previous findings in the fields of mechanotransduction and biochemistry to build up a model of the underlying biological interactions on-going at the cell-material interface. The biological properties of the material were mainly attributed to two parameters affecting the cell local environment: extracellular calcium (acting through the CaSR) and material stiffness (through NMII cytoskeletal contraction and signalling). These two pathways contribute to cell differentiation and tube-like formation through activation of gene expression. This mechanistic insight could contribute to the rational design of future, proangiogenic smart biomaterials.

\section{Acknowledgements}

We are grateful to Dr. Damian Lacroix for helpful comments and data on scaffold stiffness. We thank the European Comission (European project NMP3-LA-2008-214402, ANGIOSCAFF), the Spanish Ministry of Science and Innovation (Project MAT2008-06887-C03-01) and the CIBER-BBN for funding. AA was supported by a FI-B pre-doctoral grant from the Generalitat of Catalunya. OC acknowledges the Spanish MICINN for a Ramon y Cajal contract. We wish to confirm that there are no known conflicts of interest associated with this publication and there has been no significant financial support for this work that could have influenced its outcome.

\section{References}

Adams GB, Chabner KT, Alley IR, Olson DP, Szczepiorkowski ZM, Poznansky MC, Kos CH, Pollak MR, Brown EM, Scadden DT (2006) Stem cell engraftment at the endosteal niche is specified by the calcium-sensing receptor. Nature 439: 599-603.

Aguirre A, González A, Planell JA, Engel E (2010a) Extracellular calcium modulates in vitro bone marrowderived Flk-1+ CD34+ progenitor cell chemotaxis and differentiation through a calcium-sensing receptor. Biochem Biophys Res Commun 393: 156-161.

Aguirre A, Planell JA, Engel E (2010b) Dynamics of bone marrow-derived endothelial progenitor cell/ mesenchymal stem cell interaction in co-culture and its implications in angiogenesis. Biochem Biophys Res Commun 400: 284-291.

Anderson DG, Burdick JA, Langer R (2004) Smart biomaterials. Science 305: 1923-1924.

Asahara T, Murohara T, Sullivan A, Silver M, van der Zee R, Li T, Witzenbichler B, Schatteman G, Isner JM (1997) Isolation of putative progenitor endothelial cells for angiogenesis. Science 275: 964-966.

Brown EM, MacLeod RJ (2001) Extracellular calcium sensing and extracellular calcium signaling. Physiol Rev 81: 239-297.

Byfield FJ, Reen RK, Shentu TP, Levitan I, Gooch KJ (2009) Endothelial actin and cell stiffness is modulated by substrate stiffness in 2D and 3D. J Biomech 29: 1114-1119.

Chang W, Tu C, Chen T-H, Bikle D, Shoback D (2008) The extracellular calcium-sensing receptor $(\mathrm{CaSR})$ is a critical modulator of skeletal development. Sci Signal 1: ral.

Day RM (2005) Bioactive glass stimulates the secretion of angiogenic growth factors and angiogenesis in vitro. Tissue Eng 11: 768-777.

Engler AJ, Sen S, Sweeney HL, Discher DE (2006) Matrix elasticity directs stem cell lineage specification. Cell 126: 677-689. 
Forster NA, Penington AJ, Hardikar AA, Palmer JA, Hussey A, Tai J, Morrison WA, Feeney SJ (2011) A prevascularized tissue engineering chamber supports growth and function of islets and progenitor cells in diabetic mice. Islets 3: 271-283.

Fuchs S, Motta A, Migliaresi C, James C (2006) Outgrowth endothelial cells isolated and expanded from human peripheral blood progenitor cells as a potential source of autologous cells for endothelialization of silk fibroin biomaterials. Biomaterials 27: 5399-5408.

Goeckeler ZM, Bridgman PC, Wysolmerski RB (2008) Nonmuscle myosin II is responsible for maintaining endothelial cell basal tone and stress fiber integrity. Am J Physiol Cell Physiol 295: C994-1006.

Hammond CM, White D, Tomic J, Shi Y, Spaner DE (2007) Extracellular calcium sensing promotes human B-cell activation and function. Blood 110: 3985-3995.

Hench LL, Polak JM (2002) Third-generation biomedical materials. Science 295: 1014-1017.

Holmes K, Roberts O, Thomas A (2007) Vascular endothelial growth factor receptor-2: structure, function, intracellular signalling and therapeutic inhibition. Cell Signal 19: 2003-2012.

Ingber DE (2008) Tensegrity-based mechanosensing from macro to micro. Prog Biophys Mol Biol 97: 163-179.

Ingber D (2006) Cellular mechanotransduction: putting all the pieces together again. FASEB J 20: 811-827.

Kanczler JM, Oreffo ROC (2008) Osteogenesis and angiogenesis: the potential for engineering bone. Eur Cell Mater 15: 100-114.

Kirkpatrick CJ, Fuchs S, Unger RE (2011) Co-culture systems for vascularization - learning from nature. Adv Drug Deliv Rev 63: 291-299.

Kneser U, Polykandriotis E, Ohnolz J, Heidner K, Grabinger L, Euler S, Amann KU, Hess A, Brune K, Greil P, Stürzl M, Horch RE (2006) Engineering of vascularized transplantable bone tissues: induction of axial vascularization in an osteoconductive matrix using an arteriovenous loop. Tissue Eng 12: 1721-1731.

Koffler J, Kaufman-Francis K, Yulia S, Dana E, Daria AP, Landesberg A, Levenberg S (2011) Improved vascular organization enhances functional integration of engineered skeletal muscle grafts. Proc Natl Acad Sci USA 108: 14789-14794.

Larrivée B, Karsan A (2007) Involvement of marrowderived endothelial cells in vascularization. Handb Exp Pharmacol 180: 89-114.

Li H, Daculsi R, Grellier M, Bareille R, Bourget C, Remy M, Amedee J (2011) The role of vascular actors in two dimensional dialogue of human bone marrow stromal cell and endothelial cell for inducing self-assembled network. PloS One 6: e16767.

Liu JY, Swartz DD, Peng HF, Gugino SF, Russell JA, Andreadis ST (2007) Functional tissue-engineered blood vessels from bone marrow progenitor cells. Cardiovasc Res 75: 618-628.

Liu Z, van Grunsven LA, Van Rossen E, Schroyen B, Timmermans J-P, Geerts A, Reynaert H (2010) Blebbistatin inhibits contraction and accelerates migration in mouse hepatic stellate cells. Br J Pharmacol 159: 304-315.
Lugus J, Chung Y, Mills J, Kim S (2007) GATA2 functions at multiple steps in hemangioblast development and differentiation. Development 405: 393-405.

Lutolf MP, Gilbert PM, Blau HM (2009) Designing materials to direct stem-cell fate. Nature 462: 433-441.

Mammoto A, Ingber DE (2009) Cytoskeletal control of growth and cell fate switching. Curr Opin Cell Biol 21: 864-870.

Mammoto A, Mammoto T, Ingber DE (2008) Rho signaling and mechanical control of vascular development. Curr Opin Hematol 15: 228-234.

Mammoto A, Connor KM, Mammoto T, Yung CW, Huh D, Aderman CM, Mostoslavsky G, Smith LEH, Ingber DE (2009) A mechanosensitive transcriptional mechanism that controls angiogenesis. Nature 457: 1103-1108.

Martin D, Galisteo R, Gutkind JS (2009) CXCL8/IL8 stimulates vascular endothelial growth factor (VEGF) expression and the autocrine activation of VEGFR2 in endothelial cells by activating NF-kB through the CBM (Carma3/Bcl10/Malt1) complex. J Biol Chem 284: 6038 -6042 .

Mentaverri R, Yano S, Chattopadhyay N, Petit L, Kifor O, Kamel S, Terwilliger E, Brazier M, Brown E (2006) The calcium sensing receptor is directly involved in both osteoclast differentiation and apoptosis. FASEB J 20: 2562-2564.

Mooney DJ, Vandenburgh H (2008) Cell delivery mechanisms for tissue repair. Cell Stem Cell 2: 205-213.

Navarro M, Ginebra MP, Planell JA, Zeppetelli S, Ambrosio L (2004) Development and cell response of a new biodegradable composite scaffold for guided bone regeneration. J Mater Sci Mater Med 15: 419-422.

Nomi M, Atala A, Coppi PD, Soker S (2002) Principals of neovascularization for tissue engineering. Mol Aspects Med 23: 463-483.

Rehfeldt F, Engler AJ, Eckhardt A, Ahmed F, Discher DE (2007) Cell responses to the mechanochemical microenvironment - implications for regenerative medicine and drug delivery. Adv Drug Deliv Rev 59: 1329-1339.

Santos MI, Reis RL (2010) Vascularization in bone tissue engineering: physiology, current strategies, major hurdles and future challenges. Macromol Biosci 10: 12-27.

Sanzana ES, Navarro M, Macule F, Suso S, Planell JA, Ginebra MP (2008) Of the in vivo behavior of calcium phosphate cements and glasses as bone substitutes. Acta Biomater 4: 1924-1933.

Silver IA, Murrills RJ, Etherington DJ (1988) Microelectrode studies on the acid microenvironment beneath adherent macrophages and osteoclasts. Exp Cell Res 175: 266-276.

Spencer VA, Xu R, Bissell MJ (2010) Gene expression in the third dimension: the ECM-nucleus connection. J Mammary Gland Biol Neoplasia 15: 65-71.

Takahashi T, Kalka C, Masuda H, Chen D, Silver M, Kearney M, Magner M, Isner JM, Asahara T (1999) Ischemia- and cytokine-induced mobilization of bone marrow-derived endothelial progenitor cells for neovascularization. Nature Med 5: 434-438.

Tommila M, Jokilammi A, Terho P, Wilson T, Penttinen R, Ekholm E (2009) Hydroxyapatite coating of cellulose 
sponges attracts bone-marrow-derived stem cells in rat subcutaneous tissue. J R Soc Interface 6: 873-880.

Wang HH, Tanaka H, Qin X, Zhao T, Ye L-H, Okagaki T, Katayama T, Nakamura A, Ishikawa R, Thatcher SE, Wright GL, Kohama K (2008) Blebbistatin inhibits the chemotaxis of vascular smooth muscle cells by disrupting the myosin II-actin interaction. Am J Physiol Heart Circ Physiol 294: H2060-2068.

Xynos ID, Edgar AJ, Buttery LD, Hench LL, Polak JM (2000) Ionic products of bioactive glass dissolution increase proliferation of human osteoblasts and induce insulin-like growth factor II mRNA expression and protein synthesis. Biochem Biophys Res Commun 276: 461-465.

Xynos ID, Edgar AJ, Buttery LD, Hench LL, Polak JM (2001) Gene-expression profiling of human osteoblasts following treatment with the ionic products of Bioglass 45S5 dissolution. J Biomed Mater Res 55: 151-157.

\section{Discussion with Reviewers}

Reviewer I: The authors use blebbistatin, which is known to rapidly and locally decouple the cytoskeleton from the plasma membrane, thereby disrupting cell migration and cytokinesis but without affecting mitosis. Blebbistatin therefore is expected to disrupt cell elongation. The authors conclude that this is a proof that mechanosensation is involved in EPC tube formation, but this is a major overinterpretation of such results. It is indeed very likely that blebbistatin would have similar effects on every material (e.g. TCPS or PLA). Surprisingly, the authors mention that blebbistatin at this dose did not affect chemotaxis. It is hard to believe that blebbistatin strongly affects the elongation of EPCs, but has no inhibitory effect on migration. Is blebbistatin therefore a good choice? Are there alternative approaches/drugs?

Authors: 1) In our experiments, blebbistatin was used at a low concentration $(20 \mu \mathrm{M}$, less than half of that used by Engler et al. (2006) and other authors). At this concentration, we never observed disruption of cell motility, chemotaxis or cell death, even after $3 \mathrm{~d}$ of continuous administration. We wanted to exclude the possibility of our results being produced by a possible cytotoxicity. In that respect, we are well below the slightest sign of toxicity. 2) At the concentration used in the experiments, we did not observe a disruption of cell elongation caused by blebbistatin. The only visible change in cell morphology was a tendency of the cell to partially shrink around the edges. All other cells parameters tested (survival, etc.) were normal. However, the reviewer is right in noticing that blebbistatin could affect cell elongation, thus the effect would be the same in PLA, TCPS, etc. We took further precautions to prevent this problem by always applying blebbistatin $4 \mathrm{~h}$ or $24 \mathrm{~h}$ after cell seeding, thus allowing the cells to adhere and elongate under normal and equal starting conditions for all materials. 3) Reports on the effects of blebbistatin over cell chemotaxis are contradictory. Some authors find enhanced motility (Liu et al., 2010; Niggli et al., 2006), while others inhibition (Wang et al., 2008). These discrepancies might arise from the different cell types and concentrations employed. For our experiment, we empirically determined the effects of blebbistatin over chemotaxis and cell survival. These data were not included in the original manuscript submission for lack of space and because they do not add any information to the findings of the manuscript itself. In those experiments, we find no effect of blebbistatin on EPC migration or survival at the concentrations used in our experiments $(20 \mu \mathrm{M})$.

\section{Additional Reference}

Niggli V, Schmid M, Nievergelt A (2006) Differential roles of Rho-kinase and myosin light chain kinase in regulating shape, adhesion, and migration of HT1080 fibrosarcoma cells. Biochem Biophys Res Commun 343: 602-608. 